\title{
Pobreza e espaço: padrões de segregação em São Paulo
}

\author{
HAROLDO DA GAMA TORRES, EDUARDO MARQUES, \\ MARIA PAULA FERREIRA e SANDRA BITAR
}

\section{Introdução}

$\mathrm{E}$

STE ARTIGo apresenta resultados de uma pesquisa em andamento que analisa várias dinâmicas sociais da R egião M etropolitana de São Paulo. Esse projeto integra o Centro de Estudos da M etrópole (CEM ), que desenvolve estudos acadêmicos e trabal hos orientados para o apoio a políticas públicas locais ${ }^{1}$. 0 presente trabal ho se insere nessa iniciativa, sendo realizado em conjunto com a Secretaria de Assistência Social da Prefeitura do M unicípio de São Paulo, com o objetivo de delimitar situações de vulnerabilidade urbana de forma a orientar suas políticas. Estivemos envolvidos em projetos semelhantes sobre políticas educacionais para as prefeituras das cidades de M auá, Guarulhos, Embu e São Paulo, todas dentro da Região M etropolitana de São Paulo, o que nos trouxe um certo acúmulo, tanto em termos conceituais e metodológicos como empíricos.

Aqui serão analisados os padrões espaciais de distribuição de situações de vulnerabilidade social em São Paulo. Para tal, submetemos as informações sociodemográficas do C enso de 2000 para os 21 mil setores censitários da R egião M etropolitana de São Paulo (C enso 2000) a tratamento quantitativo (análises fatorial e de agrupamentos) com base em um Sistema de I nformações G eográficas (SI G ). U tilizando tais procedimentos, conseguimos identificar tanto a heterogeneidade da pobreza como pontos críticos de extrema precariedade social. Esses resultados, para além da dinâmica da produção do conhecimento, subsidiam a constituição de políticas sociais melhor focalizadas. Considerando as limitações de espaço a que um artigo desse tipo está sujeito, apresentaremos apenas a primeira parte do estudo - a análise fatorial.

$\mathrm{N}$ a Seção 2 é apresentada uma rápida revisão da literatura sobre a pobreza urbana em São Paulo, enfatizando os elementos mais importantes do debate baseados em nossa perspectiva. No que diz respeito à literatura, destacamos a idéia de que a pobreza tem um componente espacial que pode ser caracterizado, na maioria dos casos, como um processo de segregação. Além disso, problematizamos o papel do Estado na produção da segregação e a questão de como mensurar a pobreza em um lugar como São Paulo, considerando-se as múltiplas dimensões do fenômeno. 
Sustentamos, entretanto, que a pobreza e os espaços em que os pobres residem são muito mais heterogêneos do que geralmente considera a literatura. Essa heterogeneidade pode ser reproduzida pela análise fatorial, apresentada na Seção 3, considerando não apenas seus aspectos espaciais, mas também aqueles associados com o gênero, a falta de escolaridade etc.

A presentamos também, na Seção 4, dados sobre outras dinâmicas sociais: número de homicídios e desempenho médio dos estudantes da rede pública em provas de Língua Portuguesa. Esses dados não integraram a análise fatorial, mas acrescentaram elementos à complexidade descrita a partir das informações do Censo. Eles foram produzidos com base em um Sistema de I nformações G eográficas e indicam a existência de alguns pontos críticos nas políticas sociais, sugerindo a existência de diferentes níveis de segregação mesmo dentro das áreas mais pobres, assim como intensa superposição de carências em certas áreas.

\section{0 debate sobre periferia, segregação e pobreza urbana}

D esde os anos de 1970, a sociologia brasileira tem analisado intensamente a pobreza urbana. Espaços urbanos ocupados por esses grupos sociais foram caracterizados como "periferias" - espaços socialmente homogêneos, esquecidos pelas políticas estatais, e localizados tipicamente nas extremidades da área metropolitana ${ }^{2}$. Tais espaços são constituídos predominantemente em um loteamento irregular ou ilegal de grandes propriedades, sem o cumprimento das exigências para a aprovação do assentamento no município. A maioria das casas desses locais é "autoconstruída" 3 . E ssa solução de moradia tornou-se predominante em São Paulo, embora as favelas (uma outra solução de moradia tradicional para os pobres) também estivessem presentes ${ }^{4}$.

Supunha-se que a configuração urbana geral fosse radial-concêntrica em sua geometria (Abreu, 1987; Brasileiro, 1976), com um pronunciado declínio do valor das terras, das atividades econômicas e das condições de vida a partir do centro em direção à periferia da cidade (Bonduki e Rolnik, 1982; Villaça, 1999; e Taschner e Bógus, 2000). Em outras palavras, seria possível argumentar que esse modo de entender a forma urbana seria "dual", contrastando fortemente 0 centro rico com as periferias muito pobres e com piores serviços públicos. Entretanto, essas características de homogeneidade e localização das periferias têm sido ultimamente questionadas de vários modos:

- o surgimento de vários novos empreendimentos urbanos fechados na zona oeste da Região M etropolitana, tradicionalmente ocupada pelos pobres (Caldeira, 2000); com isso, desfaz-se a geometria radial-concêntrica e ocorre um aumento significativo da heterogeneidade social nessa região, embora a ocupação desses condomínios tenda a produzir enclaves sem quase nenhum contato entre os grupos sociais;

- um processo de disseminação da pobreza e de pobres por toda a cidade, que levou ao desenvolvimento de uma nova onda de favelas, marcada 
por múltiplas invasões de porções muito pequenas de terra não ocupadas pela urbanização, tais como pequenos espaços entre pontes e margens de rios ou linhas férreas ${ }^{5}$;

- um novo fator de mudança gerado pelo Estado, que se tornou cada vez mais presente nas periferias, levando a um significativo aumento de vários indicadores sociais, especialmente os relacionados ao acesso a serviços públicos. Esse fato pode ser em parte explicado pela intensa pressão dos movimentos sociais urbanos durante o processo de mobilização política que marcou a sociedade brasileira na década de $1980^{6}$. Entretanto, essas periferias foram também objeto de várias políticas dinamizadas pelo aparelho estatal durante as décadas de 1980 e 1990, como demonstram os estudos de M arques (2000) e Watson (1992) ${ }^{7}$. É muito provável que os dois processos tenham reforçado um ao outro (M arques e Bichir, 2001).

Em relação aos indicadores sanitários, toda essa transformação significou quase uma universalização, até o ano 2000, do fornecimento de água e coleta de lixo nas mais importantes cidades brasileiras. N o entanto, o mesmo não se aplica à rede de esgotos. Em outras palavras, os movimentos sociais e as políticas públicas introduziram importantes transformações nas periferias, exigindo uma reconsideração de antigos modelos analíticos que descreviam e investigavam essas concentrações populacionais nas décadas de 1970 e 1980. A proposição desse novo arcabouço conceitual é uma tarefa intelectual que ainda precisa ser realizada.

O s serviços e investimentos estatais, no entanto, não foram suficientes para elevar as condições de vida da população de baixa renda ao padrão das outras partes das cidades ( $M$ arques e Bichir, 2001). I sso se deve em parte ao tamanho do deficit entre essas condições de vida e um verdadeiro acesso a serviços e infraestrutura, e também à qual idade dos serviços e equipamentos recentemente implantados pelo governo nessas áreas. $\mathrm{N}$ a grande maioria dos casos, as obras realizadas ali eram (e ainda são) de baixa qualidade. Assim, as melhorias públicas feitas nessas áreas não eram finalizadas e tendiam a deteriorar-se, pois a lógica sistêmica da infra-estrutura urbana não era respeitada.

Em vários aspectos, esses processos contribuíram para a diferenciação dos grupos so ciais urbanos pobres e seus territórios, fazendo das periferias (bem como das favelas) um fenômeno cada vez mais heterogêneo. Essa dimensão introduziu novos desafios conceituais e analíticos visto que, ao contrário dos anos de 1970, a simples classificação de um espaço como periferia já não nos permite prever os conteúdos sociais associados à moradia no local. E mbora o desenvolvimento de um novo quadro conceitual seja uma tarefa complexa e necessariamente coletiva, esperamos que os elementos enfocados nas próximas seções apontem nesta direção.

\subsection{Segregação social}

N o caso de São Paulo, a pobreza urbana não é só uma questão de nível, ou índice, mas também de concentração espacial e social, envolvendo desigualdade, 
separação e homogeneidade espacial. Esse problema também está ligado às políticas públicas, que deveriam ser criadas para melhorar a situação dessas pessoas. O problema não é novo, nem está ausente das cidades norte-americanas e européias. A literatura da área de C iências Sociais acumulou um conhecimento considerável não apenas sobre os antigos processos de segregação que marcaram cidades como $\mathrm{N}$ ova York e $\mathrm{D}$ etroit, mas também sobre as dinâmicas de novas formas de segregação e pobreza urbana ( $\mathrm{H}$ arloe et al., 1992; M arcuse, 1996; L ogan et al., 1992 ${ }^{8}$ que levaram a novas formas de protesto urbano (J encks, 1993) ${ }^{9}$. E mbora a questão da desigualdade e da falta de eqüidade na distribuição dos benefícios da urbanização esteja presente no debate internacional, há uma forte ênfase na questão da separação entre grupos sociais e da homogeneidade social das várias partes da cidade, estruturada especialmente pela etnia e pela raça.

G eralmente, a segregação nas cidades brasileiras é semelhante, com a pobreza tendendo a ser altamente concentrada em termos espaciais. No entanto, no Brasil a ênfase da literatura sempre esteve mais na existência de desigualdades e injustiças na distribuição da renda e dos serviços públicos do que na separação dos grupos sociais. Esses dois elementos estão obviamente associados empiricamente, assim como se imbricam nos processos que produzem o espaço urbano, mas enquanto na literatura internacional há forte ênfase na questão da análise da homogeneidade de cada espaço em particular, no caso nacional essa dimensão está praticamente ausente, sendo o foco centrado nas desigualdades. Por outro lado, parece muito mais difícil combater a pobreza por meio das políticas públicas no Brasil, visto que a pobreza acumulada é enorme e os processos que a reproduzem estão mesclados com vários aspectos de reprodução social ${ }^{10}$.

U ma importante conseqüência social da fusão entre desigualdade e a segregação é o forte efeito cumulativo dos riscos sociais e ambientais em alguns pontos críticos que chamamos de "hiperperiferias" (Torres e M arques, 2001). $\mathrm{N}$ a verdade, o nível dos problemas sociais e ambientais de determinadas áreas é impressionante, superpondo, em termos espaciais (e sociais), os piores indicadores socioeconômicos, com riscos de enchentes e deslizamentos de terra, um ambiente intensamente poluído e serviços sociais (quando os há) extremamente ineficientes (Torres, 1997) ${ }^{11}$.

E mbora a presença de populações pobres nas periferias e favelas não esteja em discussão, as causas de sua concentração espacial são objeto de debate. A literatura brasileira na área geralmente enfatiza três diferentes grupos de causas para esse padrão de urbanização:

- o mercado detrabal ho ea estrutura social - para essa literatura, a segregação urbana é uma conseqüência do mercado de trabal ho, como nos trabalhos resenhados por Valladares e C oelho (1987). Para eles, a natureza da estrutura social brasileira e seu mercado de trabalho, bem como as recentes transformações pelas quais passaram, explicariam os padrões de alta segregação e as baixíssimas condições de vida nas periferias. A po- 
breza urbana no Brasil não seria um mero problema de integração na sociedade industrial moderna, mas um traço estrutural da economia capitalista dos países em desenvolvimento ${ }^{12}$;

- a dinâmica do mercado imobiliário eda produção demoradias- algunsautores enfatizam os incorporadores e suas estratégias. D e acordo com essa linha de raciocínio, a estrutura urbana seria explicada em grande parte por esses atores, que teriam o poder de controlar as melhores localizações, especular com a terra desocupada e lucrar com mudanças na utilização das propriedades e suas redondezas (Ribeiro, 1997) ${ }^{13}$. O utros autores concentram-se no modo como o mercado imobiliário aloca grupos sociais e atividades econômicas por meio de mecanismos microeconômicos de valorização da terra; esses fatores promovem a segregação dos mais pobres por meio da competição pelo uso da terra (Smolka, 1987 e Abramo, 1994);

- políticasestatais- um outro grupo de autores focaliza o poder regulador do Estado sobre o território. De acordo com essas análises, o Estado pode manter privilégios e excluir uma parte significativa da cidade dos benefícios da urbanização por meio da legislação sobre a construção civil e o uso do solo (Rolnik, 1997 e N éri, 2002). U m elemento central aqui seria o zoneamento, que "congelaria" os benefícios da urbanização em determinadas partes da cidade habitadas pelos grupos mais ricos, ao mesmo tempo em que permite vários tipos de padrões de uso e de construção no restante da cidade. O utros estudos apontam padrões de segregação promovidos ou incrementados pela ação direta do Estado (Fix, 2001; M arques e Bichir, 2001; Vetter, 1975 e Vetter et al., 1981); aqui, as causas seriam o aumento do valor da terra em certas partes da cidade, resultante de investimentos públicos ou de obras públicas, os quais podem expulsar alguns grupos sociais ou substituí-los por outros (Vetter, 1975 e Vetter et al., 1981) ${ }^{14}$, ou mesmo a ação direta do Estado deslocando compulsoriamente populações de baixa renda (Fix, 2001).

É muito provável que os três processos descritos acima ocorram simultaneamente. É verdade que famílias localizadas na base da estrutura social tendem a viver em condições mais precárias e a ter escolhas muito limitadas, especialmente na sociedade brasileira, onde a ascensão social é restrita. $M$ as também é verdade que o mercado imobiliário está estruturado em torno de ofertas de uso e locação do solo, e que a maioria da população não pode pagar quase nada para morar. Essas pessoas tendem a ser empurradas para lugares sem serviços públicos e com quase nenhuma renda diferencial. No entanto, também é verdade que o Estado pode incrementar esses processos, ou mesmo causar ou multiplicar a segregação e a produção de desigualdades de maneira direta e concentrada.

\subsection{Mensuração da pobreza}

U m dos principais problemas do estudo das desigualdades sociais está em definir o que é pobreza e como mensurá-la. 0 modo mais comum de tratar essa 
questão é adotar uma linha de pobreza. As linhas de pobreza são, em geral, consideradas como a renda mínima necessária para a sobrevivência da família. Podem ainda se referir a uma definição mais ampla de pobreza, normalmente associada a algum programa específico de assistência social ( $M$ ingione, 1999). A pesar de sua grande utilidade em termos de comparações internacionais, as linhas de pobreza são controversas. Elas podem, por exemplo, descaracterizar a situação dos pobres urbanos em virtude de os al uguéis e os custos de transporte serem mais al tos nos centros urbanos maiores. Elas também não consideram as rendas não monetárias, que são comuns nas áreas rurais e nas comunidades pobres. Finalmente, as linhas de pobreza não necessariamente captam as assim chamadas "múltiplas dimensões da pobreza" . A idéia subjacente a esse conceito é de que a pobreza não pode ser definida apenas em termos materiais de sobrevivência, mas deve considerar também os indivíduos e as famílias que, apesar de sobreviverem, não estão incluídos nos mais importantes benefícios das sociedades urbanas, tais como educação, saneamento básico, saúde, integração cultural e social (M ingione, 1999). Portanto, embora estejam acima da linha de pobreza em alguns momentos de sua vida, muitas famílias tornam-se extremamente frágeis, por exemplo, quando ocorre uma doença grave ou morte entre seus membros ${ }^{15}$.

Além disso, em uma grande região metropolitana como São Paulo, que no ano 2000 concentrava 18 milhões de pessoas, o problema da localização da pobreza não é nada simples. E mbora políticas de redução de pobreza sejam dirigidas a esses grupos sociais, quando os recursos são escasso s existe uma tendência a não investir nas regiões menos "visíveis", nas quais vivem os extremamente pobres.

Considerando-se esses elementos, a estratégia empírica desenvolvida neste estudo baseou-se nos seguintes elementos:

- os dados precisariam ser extremamente desagregados, a fim de garantir a observação detal hada dos grupos so ciais e suas características socioeconômicas; para tanto, utilizamos um SIG com os 21 mil setores censitários da Região M etropolitana de São Paulo (2000);

- a questão da múltipla dimensão da pobreza deveria ser considerada. C omo conseqüência, em vez de adotar uma única linha de pobreza, ou de utilizar apenas a distribuição de renda, construímos um indicador de privação com base nos dados sobre renda média, número de famílias abaixo da linha da pobreza, escolaridade, gênero e tamanho da família. A criação desse indicador baseou-se em uma análise fatorial (análise de componentes) ${ }^{16}$;

- também é importante avaliar como indicadores sociais diferentes, que não foram incluídosno modelo - tais como a taxa de homicídios - correlacionam-se com os fatores produzidos pelo modelo estatístico; essa associação foi possível em virtude dos recursos do SI G , como o endereçamento automático, que permite a localização de cada óbito como um ponto no mapa $^{17}$. 
A combinação dessas técnicas permitiu, por um lado, uma grande desagregação da informação e, por outro, a manipulação de uma grande quantidade de dados dentro do contexto de um modelo estatístico relativamente simples. 0 resultado final é uma descrição detalhada da distribuição espacial da pobreza. Essa estratégia pode ser muito útil, ajudando os governos locais e nacionais a destinar recursos públicos para os mais necessitados e também contribuindo para um entendimento mais profundo da pobreza urbana em São Paulo. O s principais resultados desse exercício são detal hados a seguir.

\section{Análise fatorial}

A utilização de uma análise fatorial permitiu identificar - para um grupo concreto de regiões - quais variáveis, em termos de educação, condições de moradia etc., estão relacionadas aos altos níveis de pobreza, levando-nos ao desenvolvimento de um "indicador de privação", que ajuda a captar as múltiplas dimensões da pobreza. O utra vantagem dessa técnica está em reduzir os problemas associados com a informação sobre a renda, que tende a ser sub-registrada no Brasil. U m procedimento similar foi empregado, por exemplo, pelo Conapo (Consejo N acional de Población) no M éxico, ao definir os alvos para um programa social de transferência de renda denominado Progresa (Rubalcava e O rdaz, 1999).

A Tabela 1 apresenta todas as variáveis que foram consideradas na análise fatorial e indica aquelas que permaneceram no modelo para a criação dos dois fatores. Certas variáveis não mostram uma variação significativa entre os diferentes setores censitários e foram retiradas do estudo. Por exemplo, a maioria dos indicadores de condições de moradia (como água encanada - 98\%, coleta de lixo 97\%, e domicílios com banheiro - 99\%) não varia, indicando a presença de coberturas virtualmente universais em metrópoles como São Paulo ${ }^{18}$. N a página seguinte, apresentamos a relação entre os fatores e as variáveis originais.

O s dois fatores conseguiram explicar $76,70 \%$ da variância total ${ }^{20}$. 0 primeiro fator desenvolvido nesta análise foi denominado "Dimensão de Privação" devido às variáveis que estão entre seus componentes. Sem dúvida, o nome dado a um fator acaba representando uma certa filiação às perspectivas teóricas sobre a pobreza. Nós poderíamos tê-lo chamado de "fator de risco", "fator de exclusão" ou até de "fator de marginalidade", mas optamos pelo substantivo "privação", palavra que tem sido empregada na literatura desde a década de 1970 para tratar da questão das múltiplas dimensões da pobreza (M ingione, 1999).

O s setores com níveis mais altos do indicador de privação tendem a concentrar a população mais "frágil" no curto e longo prazos. E sses setores apresentam renda média mais baixa e índice de escolaridade inferior, maior proporção de famílias muito pobres, maior número médio de habitantes por domicílio, proporção mais alta de mulheres com baixa escolaridade chefes de família e proporção maior de adolescentes. D o nosso ponto de vista, essas famílias estão em situações socialmente vulneráveis, porque: 
Tabela 1 - Variáveis U tilizadas na Análise Fatorial

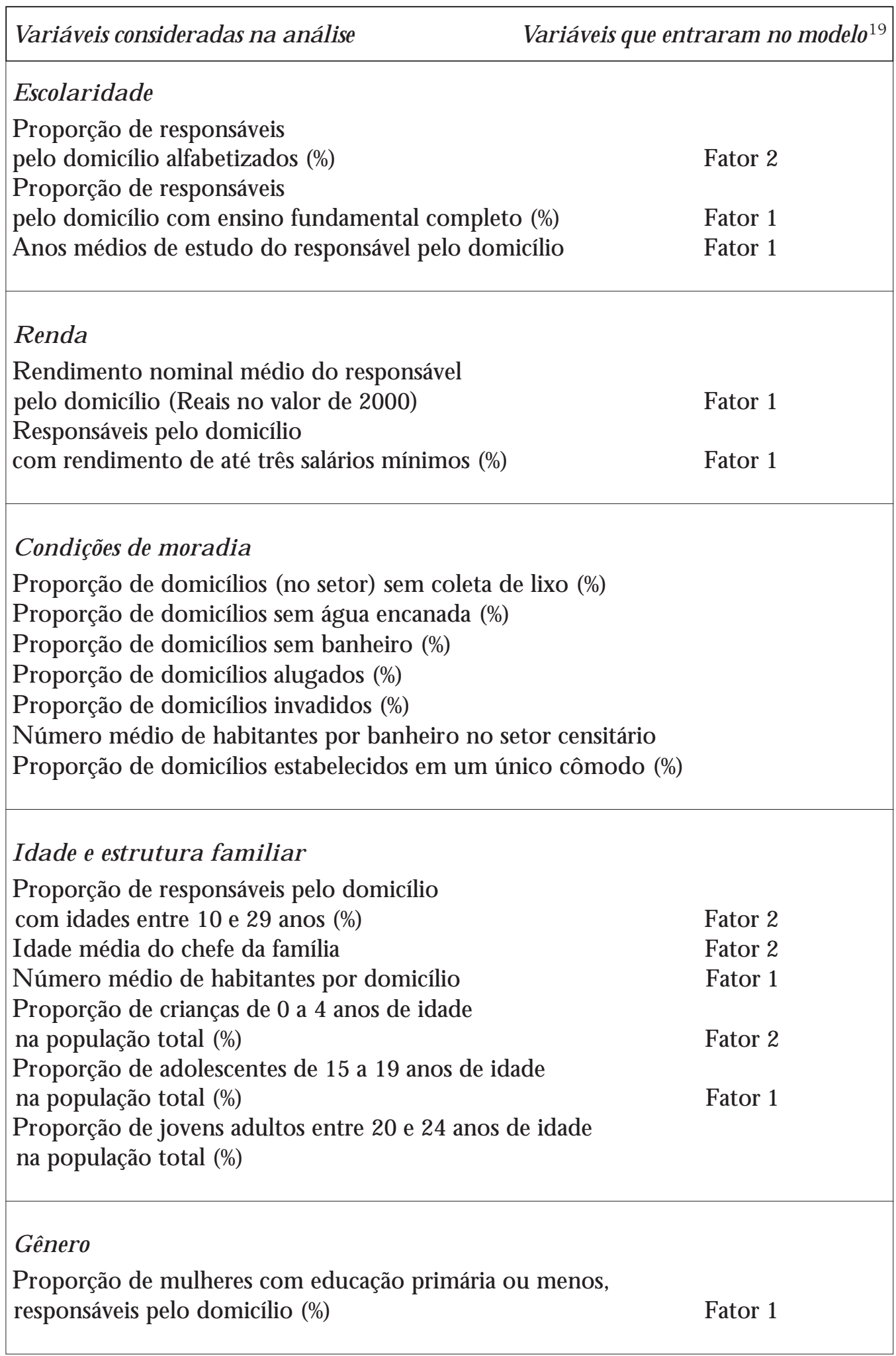


- escolaridade mais baixa significa uma capacidade reduzida de conseguir um novo emprego ou renda em caso de desemprego, assim como piores ocupações quando empregados;

- famílias chefiadas por mulheres com baixa escolaridade indicam uma renda familiar mais baixa por causa da discriminação sofrida pelas mulheres no mercado de trabalho e também porque isso significa tipicamente uma única fonte de renda familiar ${ }^{21}$;

- um maior número de pessoas por domicílio significa a necessidade de mais pessoas partilharem recursos comuns, o que traz conseqüências para a nutrição, saúde e educação. E mbora o papel do tamanho da família na configuração da pobreza seja há muito tempo controverso, pesquisas recentes indicam que esses dois elementos têm, de fato, uma relação complexa, mas real (M errick, 2002).

- uma renda mais baixa também significa piores condições de nutrição e moradia, implicando uma probabilidade mais al ta de doenças infecciosas e respiratórias. As doenças podem causar um impacto significativo na renda familiar em virtude da interrupção do trabalho - que é um grande problema para trabalhadores autônomos e não registrados - e também do custo do tratamento, apesar da presença do sistema público de saúde.

A maioria dessas correlações é bem discutida na literatura (M ingione, 1999), embora elas não sejam necessariamente óbvias. A única surpresa aqui é o fato de a proporção de adolescentes estar correlacionada à pobreza, já que esta última costuma aparecer com mais freqüência em crianças pequenas. Entretanto, essa relação reflete uma condição particular da estrutura etária de São Paulo, que sofreu um significativo declínio da fecundidade desde a década de 1980 (Bercovich, M adeira e Torres, 1998).

A Tabela 2 traz diversas variáveis descritivas relacionadas à distribuição do Índice de Privação. Como se observa, o quinto quintil pode ser considerado o pior para todas as variáveis analisadas. $\mathrm{H}$ á problemas aí não apenas nas condições socioeconômicas que formam o fator 1 , mas também porque existem maiores proporções de jovens e de mulheres de baixa escolaridade atuando como chefes de família. A maioria das favelas da cidade também está incluída nesse quintil da distribuição. Em outras palavras, condições socioeconômicas precárias têm um impacto particular em alguns grupos sociais específicos, fato que é importante para orientar estratégias políticas específicas em áreas como educação e saúde.

No entanto, a principal diferença nos indicadores está localizada entre o primeiro e o segundo quintil. Para a variável "renda média do responsável pelo domicílio", por exemplo, o valor do primeiro quintil é quase três vezes maior que 0 valor do segundo. Em uma interpretação preliminar, esse dado parece reforçar uma perspectiva "dualista" no que diz respeito à diferenciação social e espacial da Região M etropolitana de São Paulo ${ }^{22}$. Esses resultados reforçam os argumentos de autores como Villaça (2000) com relação às áreas habitadas pela 
população de mais alta renda. Entretanto, é preciso cautela com esse tipo de interpretação pela presença de heterogeneidade quando desagregamos as informações espacialmente.

Tabela 2 - Valores M édios de D iferentes Variáveis Socioeconômicas segundo Q uintis do Indicador de Privação. Setores Censitários da R egião M etropolitana de São Paulo, 2000.

\begin{tabular}{|c|c|c|c|c|c|c|c|c|c|}
\hline 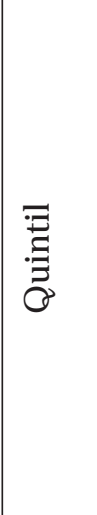 & 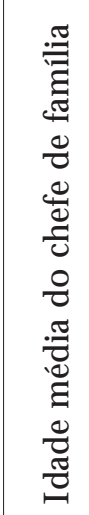 & 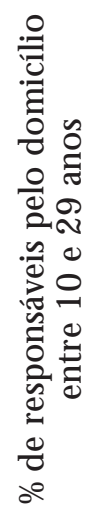 & 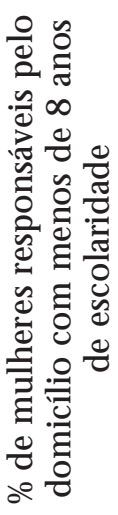 & 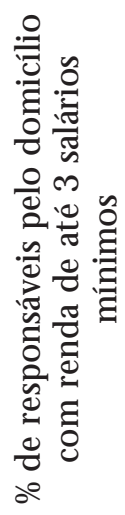 & 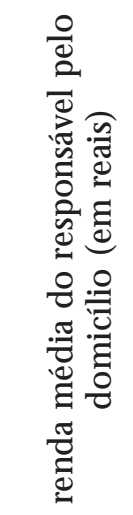 & 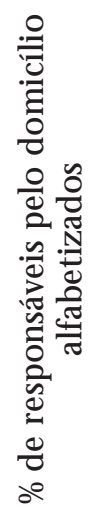 & 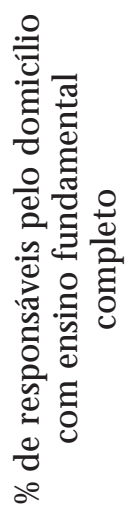 &  & 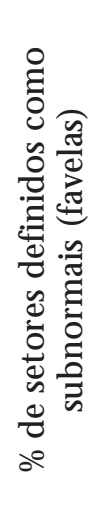 \\
\hline 10 & 46,6 & 12,0 & 10,1 & 17,7 & $2.784,1$ & 98,4 & 77,4 & 6,7 & 2,2 \\
\hline $2^{\circ}$ & 44,1 & 16,8 & 16,0 & 41,4 & 952,8 & 94,1 & 47,7 & 9,1 & 6,7 \\
\hline 3응 & 44,2 & 16,8 & 18,5 & 47,3 & 742,2 & 92,9 & 41,2 & 9,2 & 6,0 \\
\hline $4^{\circ}$ & 44,3 & 16,5 & 20,8 & 51,6 & 659,0 & 91,7 & 37,3 & 9,3 & 8,2 \\
\hline 50 & 43,4 & 17,2 & 26,0 & 59,7 & 529,2 & 89,1 & 31,6 & 9,9 & 24,3 \\
\hline RMSP & 44,5 & 15,9 & 18,2 & 43,6 & $1.116,5$ & 93,2 & 46,8 & 9,0 & 9,5 \\
\hline
\end{tabular}

Fonte: IBGE.

Para discutir essa questão, apresentamos no M apa 1 a distribuição do indicador de privação em sua dimensão espacial. É possível observar que níveis mais altos de privação estão presentes em distritos mais distantes, particularmente ao norte, leste e sul da Região M etropolitana, ao passo que os grupos mais ricos estão altamente concentrados na área central de São Paulo. Favelas também são claramente identificáveis nesse mapa, sendo representadas principalmente pelos pequenos pontos na cor marrom espal hados nas áreas leste, sul e norte da região. O bservando esse mapa e considerando o tamanho da população, é possível argumentar que o padrão de segregação mais importante em São Paulo envolve a auto-segregação das famílias ricas, historicamente agrupadas no centro da R egião M etropolitana para ter melhor acesso aos escassos serviços de infra-estrutura. Contudo, ações do capital imo biliário criaram importantes aglomerados de famílias ricas em torno de novos centros. É o caso da região oeste da metrópole. Trata-se das comunidades fechadas descritas e discutidas por Caldeira (2000). Em termos gerais, exceto nessa parte da metrópole, a privação tende a diminuir à medida que nos aproximamos do "centro" da cidade, o que seria consistente com o modelo de periferia discutido na Seção 2. 




Crianças de rua aprendem informática no Parque do I bi rapuera, em São Paulo.

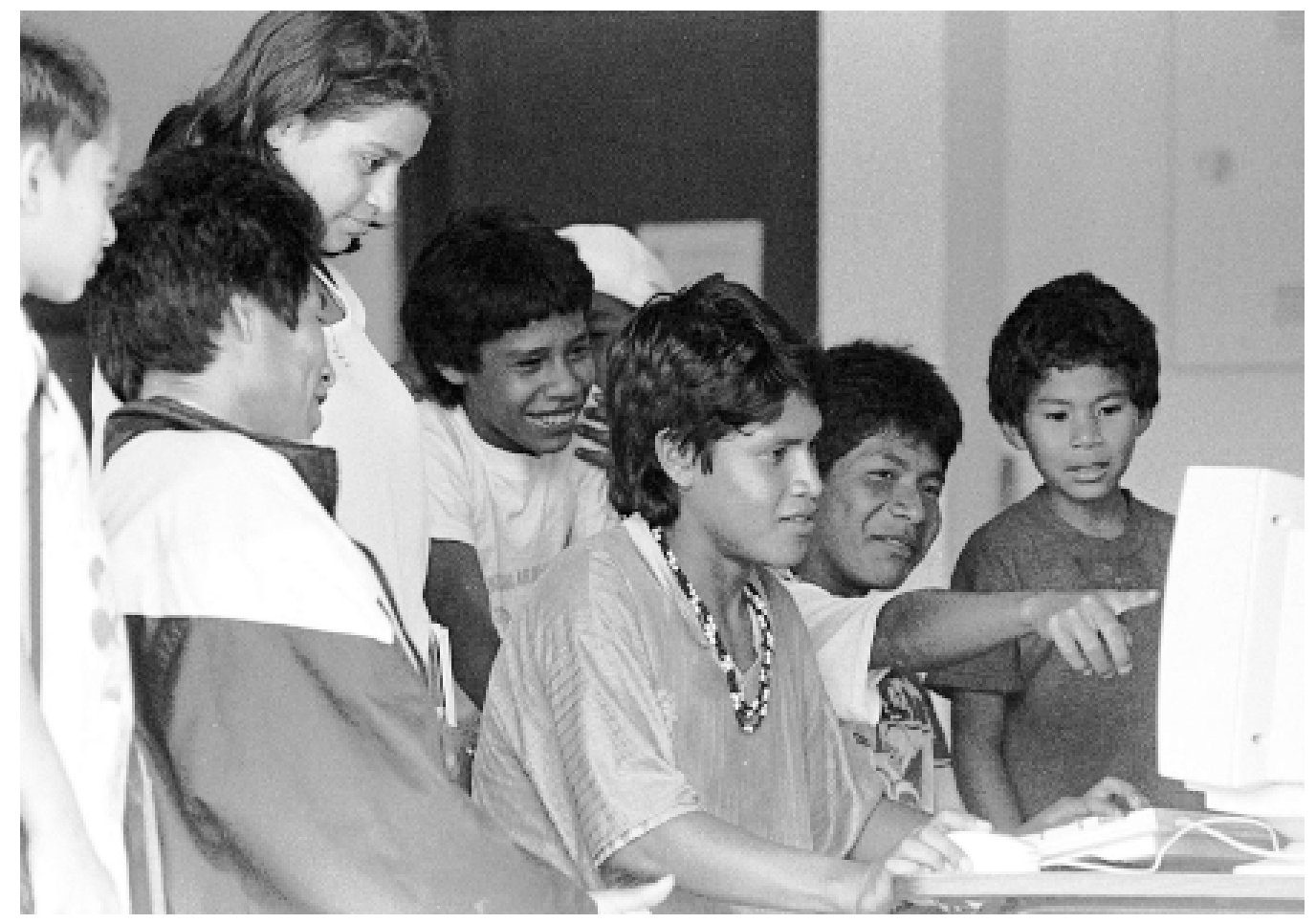

Índios Guarani recebem em Parel heiros (zona Sul) seu primei ro computador 


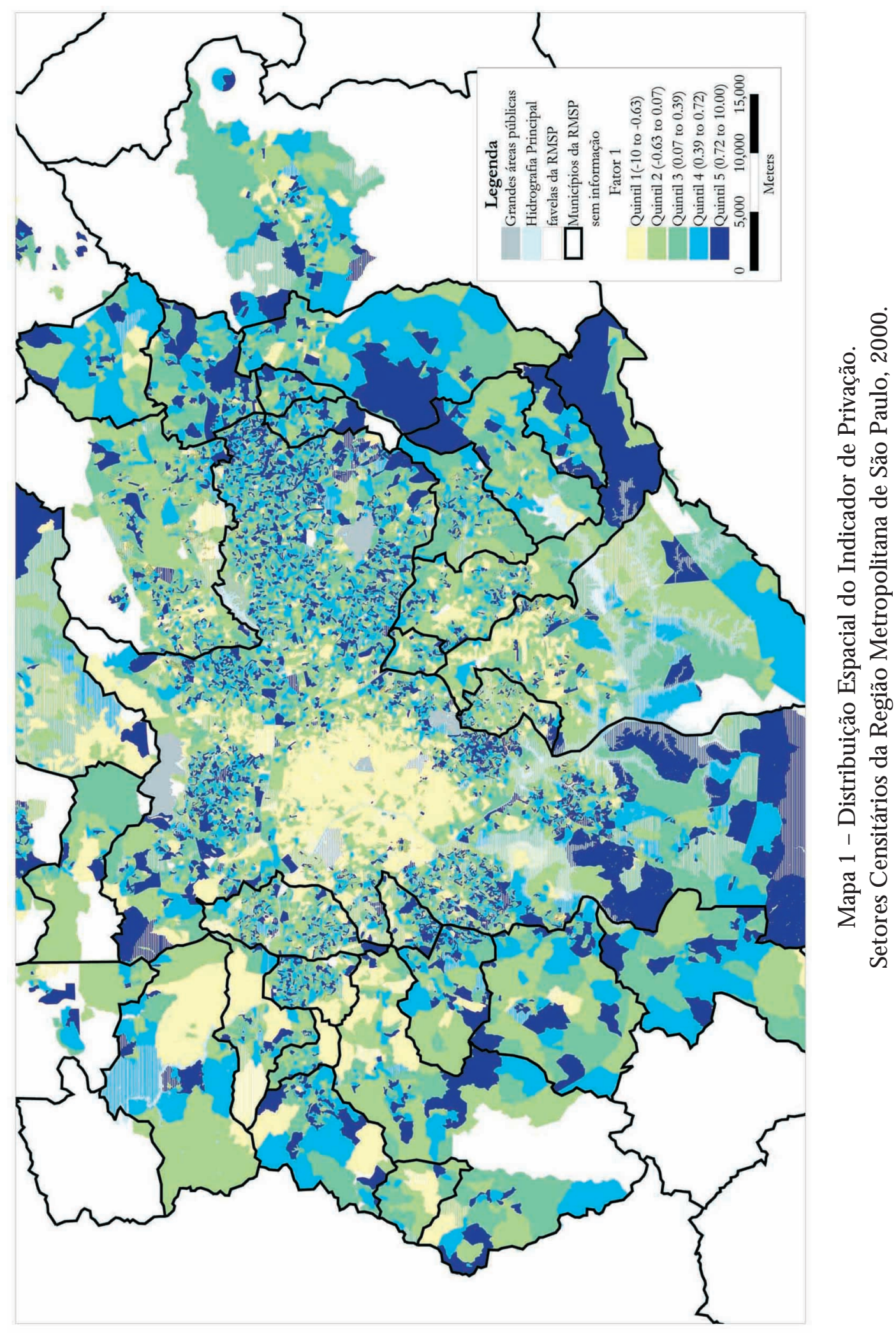


De fato, os dados agregados disponíveis confirmam que a população das periferias muito distantes sofre, em média, maiores níveis de privação do que as populações do centro da cidade e das áreas intermediárias (dois a 10 km do centro) (Tabela 3). Entretanto, o aumento significativo dos desvios-padrão do índice de privação em relação à médias por faixa de distância, à medida que se vai do centro para as periferias, mostra uma heterogeneidade substancial dentro de cada um dos "anéis" de distância, ao contrário do sustentado por autores como Taschner e Bógus (2000). N a verdade, como se pode ver no M apa 1, a distribuição espacial dos grupos sociais apresenta muitas descontinuidades e inversões, sugerindo que o modelo radial-concêntrico é uma simplificação genérica da forma urbana. Em termos urbanísticos, essas descontinuidades e inversões estão relacionadas com vários importantes subcentros preexistentes, com novos centros ricos construídos recentemente pelos capitais de incorporação, e também com as favelas ( $M$ arques e Bitar, 2002). O s problemas da estrutura centro-periferia ficam visíveis especialmente quando são consideradas distâncias superiores a $30 \mathrm{~km}$ do Centro (Tabela 3). Em outras palavras, como veremos em maior detalhe na Seção 4, o modelo radial-concêntrico esconde importantes diferenças entre as periferias.

Tabela 3 - Valores M édios de E ducação, Renda e do Indicador de Privação de acordo com a D istância M édia do Setor Censitário em relação ao Centro da Cidade, 2000.

\begin{tabular}{|c|c|c|c|c|c|c|}
\hline \multirow[t]{2}{*}{$\begin{array}{l}\text { D istância } \\
\text { em relação } \\
\text { ao centro }(*)\end{array}$} & \multicolumn{2}{|c|}{$\begin{array}{l}\text { Anos médios } \\
\text { de estudo do } \\
\text { responsável }\end{array}$} & \multicolumn{2}{|c|}{$\begin{array}{l}\text { Rendimento nominal } \\
\text { médio do responsável } \\
\text { pelo domićlio } \\
\text { (Reais em 2000) }\end{array}$} & \multicolumn{2}{|c|}{ Indicador de privaçãc } \\
\hline & M édia & $\begin{array}{l}\text { D esvio- } \\
\text { padrão }\end{array}$ & M édia & $\begin{array}{l}\text { D esvio- } \\
\text { padrão }\end{array}$ & $M$ édia & $\begin{array}{l}\text { D esvio- } \\
\text { padrão }\end{array}$ \\
\hline 0 a $2 \mathrm{~km}$ & 12,75 & 1,31 & 4760,35 & 2593,11 & $-2,03$ & 0,83 \\
\hline 2 a 5 km & 11,74 & 2,03 & 3275,00 & 1923,60 & $-1,64$ & 0,93 \\
\hline 5 a $10 \mathrm{~km}$ & 8,62 & 2,45 & 1585,56 & 1263,06 & $-0,26$ & 1,07 \\
\hline 10 a $15 \mathrm{~km}$ & 6,94 & 1,98 & 951,49 & 759,55 & 0,24 & 0,83 \\
\hline 15 a $20 \mathrm{~km}$ & 6,94 & 1,91 & 937,35 & 830,54 & 0,18 & 0,79 \\
\hline 20 a $25 \mathrm{~km}$ & 6,44 & 1,70 & 754,33 & 639,24 & 0,19 & 0,75 \\
\hline 25 a $30 \mathrm{~km}$ & 5,76 & 1,14 & 570,50 & 353,42 & 0,40 & 0,56 \\
\hline 30 a $35 \mathrm{~km}$ & 5,58 & 1,23 & 529,05 & 252,15 & 0,42 & 0,55 \\
\hline Mais de $35 \mathrm{~km}$ & 6,23 & 1,99 & 753,32 & 671,94 & 0,27 & 0,67 \\
\hline Total & 7,36 & 2,54 & 1168,90 & 1278,79 & 0,00 & 1,00 \\
\hline
\end{tabular}

(*) Consideramos o shopping I guatemi como o "centro da cidade". Trata-se do shopping center mais antigo e importante do país. Também é o cerne da região mais rica de São Paulo nos últimos tempos (Frugoli, 1998). As distâncias foram calculadas pelo SI G. 
Também é interessante notar, na Tabela 3, que o padrão radial-concêntrico de segregação parece ser muito mais forte na educação que no item renda (veja o desvio-padrão). I sso revela algumas características interessantes da dinâmica da segregação em São Paulo: é possível encontrar lugares com níveis mais altos de renda e distantes do centro - embora não com níveis muito al tos de escolaridade, como nos bairros de Santana e Tatuapé, bem como nas cidades de São Caetano e Santo André, na área sudeste da R egião M etropolitana.

Em resumo, a dimensão de privação aqui apresentada parece ser um bom indicador das desigualdades sociais da R egião M etropolitana de São Paulo. Seus componentes são consistentes com a literatura, correlacionando renda, escolaridade, tamanho das famílias e famílias chefiadas por mulheres. Sua distribuição espacial também é consistente com a literatura em termos da descrição geral das dimensões espaciais das desigual dades urbanas em São Paulo e da presença de favelas. No entanto, também foi possível observar que sua distribuição espacial apresenta descontinuidades, sugerindo que a o modelo centro-periferia não é suficiente para explicar os diferentes contextos das periferias. E ssas áreas são grandes e tendem a ser bastante heterogêneas, o que exige um significativo trabal ho empírico e um razoável esforço de elaboração conceitual para que compreendamos o que a segregação realmente significa. A seguir, trabal haremos mais esse argumento.

\section{N ovos dados sobre segregação - índices de homicídio e desempenho em provas de Língua Portuguesa}

A violência e o crime são questões emergentes em quase to dos os países da América Latina. N a Região M etropolitana de São Paulo, o índice de mortes relacionadas a homicídios e a outras formas de violência aumentou rapidamente durante a década de 1990, tendo sido usado como um importante indicador de crises sociais e da deterioração das relações sociais (C ardia, 1999 e 2000; Alesp, 2000). A Tabela 4 apresenta a distribuição do índice de homicídios para agrupamentos de setores censitários classificados segundo os quintis da análise fatorial.

É interessante observar que os índices de homicídios variam significativamente em diferentes quintis. Em termos gerais, a área que sofre menos privação (quintil 1) também apresenta os menores índices de homicídio, comparáveis com os dados para São Paulo na década de 1970 (Alesp, 2000). De forma similar, à medida que se desce nos quintis, as taxas de homicídio tendem a aumentar, especialmente se considerarmos o número de homicídios entre pessoas jovens (entre 15 e 29 anos de idade). Contudo, como veremos adiante, esse padrão espacial oculta importantes diferenças entre as periferias.

Para discutir esse problema mais a fundo, apresentamos no $M$ apa 2 a distribuição de homicídios na cidade de São Paulo. M ais uma vez, em uma consideração inicial, parece que os homicídios apresentam um óbvio "efeito periferia", que intuitivamente ratifica o "argumento dualista” da literatura ao descrever esses espaços. 


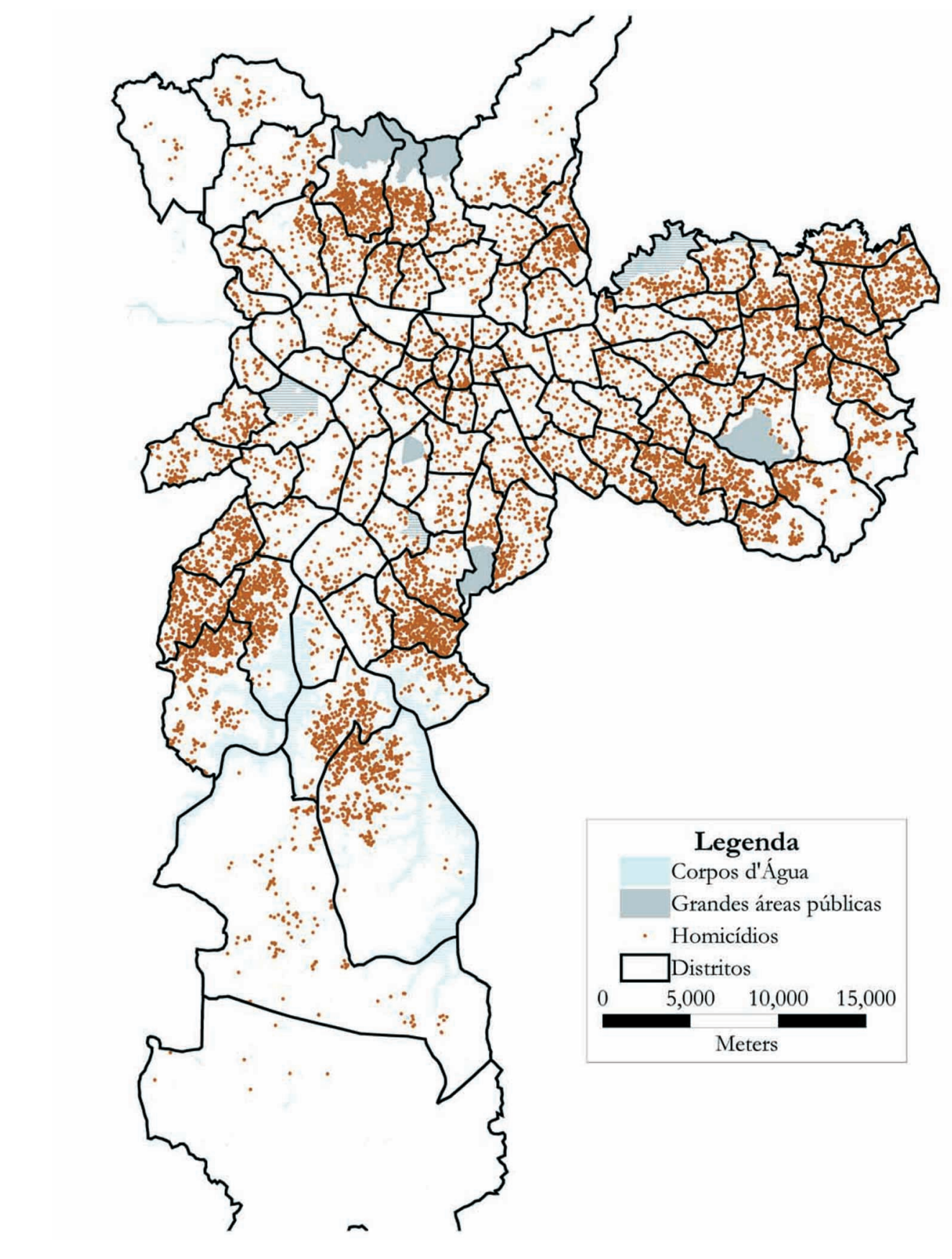

Fonte: Fundação Seade, 1998-2000.

M apa 2 - Local de Residência de Pessoas que M orreram por H omicídio na Cidade de São Paulo. 
Tabela 4 - Índice de H omicídios de acordo com Q uintis do Indicador de Privação. M unicípio de São Paulo, 2001.

\begin{tabular}{|l|c|c|c|c|}
\hline Q uintis & $\begin{array}{c}\text { Homicídios em } \\
1998-2000\end{array}$ & $\begin{array}{c}\text { H omicídios } \\
\text { por habitante } \\
\text { (em 100.000) }\end{array}$ & $\begin{array}{c}\text { H omicídios } \\
\text { de 15 a 29 } \\
\text { anos por habitante } \\
\text { (em 100.000 } \\
\text { habitantes) }\end{array}$ & $\begin{array}{c}\text { Adolescentes } \\
\text { entre 15 } \\
\text { e 19 anos } \\
\text { na população } \\
\text { total (\%) }\end{array}$ \\
\hline 1 & 1.354 & 21,70 & 44,90 & 7,8 \\
2 & 2.617 & 40,75 & 86,74 & 9,3 \\
3 & 3.022 & 49,20 & 103,73 & 9,9 \\
4 & 3.211 & 50,56 & 107,54 & 10,4 \\
5 & 3.469 & 56,66 & 119,43 & 11,3 \\
\hline Total & 13.673 & 43,71 & 94,80 & 9,8 \\
Sem localização & 351 & - & - & - \\
\hline
\end{tabular}

Fonte: Fundação Seade.

O bservação: A informação sobre homicídios baseia-se no registro civil, que fornece dados sobre a localização da residência da pessoa morta. A localização dos dados sobre homicídios em cada setor censitário foi possibilitada pela utilização de técnicas de SI G. Ver M apas 2 e 3.

E ntretanto, esses dados e o mapa dão uma indicação apenas preliminar da distribuição do fenômeno da violência, visto que o tamanho da população também varia em diferentes áreas. C onseqüentemente, também produzimos um mapa que representa o índice de homicídios por grid de um quilômetro quadrado da cidade ( $\mathrm{M}$ apa 3$)^{23}$. A observação desse mapa não nos permite confirmar que os homicídios sejam necessariamente um fenômeno relacionado à periferia, indistintamente, pois estão altamente concentrados em alguns bairros determinados como J ardim Ângela, Cidade Ademar, Brasilândia e São Rafael. 0 mapa mostra vários outros distritos com privação igual mente elevada nas áreas nordeste e leste da cidade, onde os índices de homicídio estão abaixo ou perto da média da Região M etropolitana, indicando que a mera consideração da privação (ou de um status de periferia) não é suficiente para explicar a presença de índices altos ou baixos de homicídio.

Conseqüentemente, é possível argumentar que a distribuição de índices de homicídio está longe de ser "dual", sendo concentrada em al guns "pontos críticos". Em outras palavras, não podemos afirmar que os homicídios estão perfeitamente relacionados com os níveis de renda e educação em diferentes áreas. $\mathrm{O}$ utros elementos devem ser levados em consideração. Por exemplo, 61\% de todos os homicídios que ocorreram em São Paulo entre 1998 e 2000 envolveram vítimas entre quinze e 29 anos de idade, o que sugere que a estrutura etária também é importante ${ }^{24}$. É quase certo que outros elementos - tais como o meio cultural e as dinâmicas sociais locais - também devam ser considerados quando se interpretam dados criminais (Cardia, 2000). 


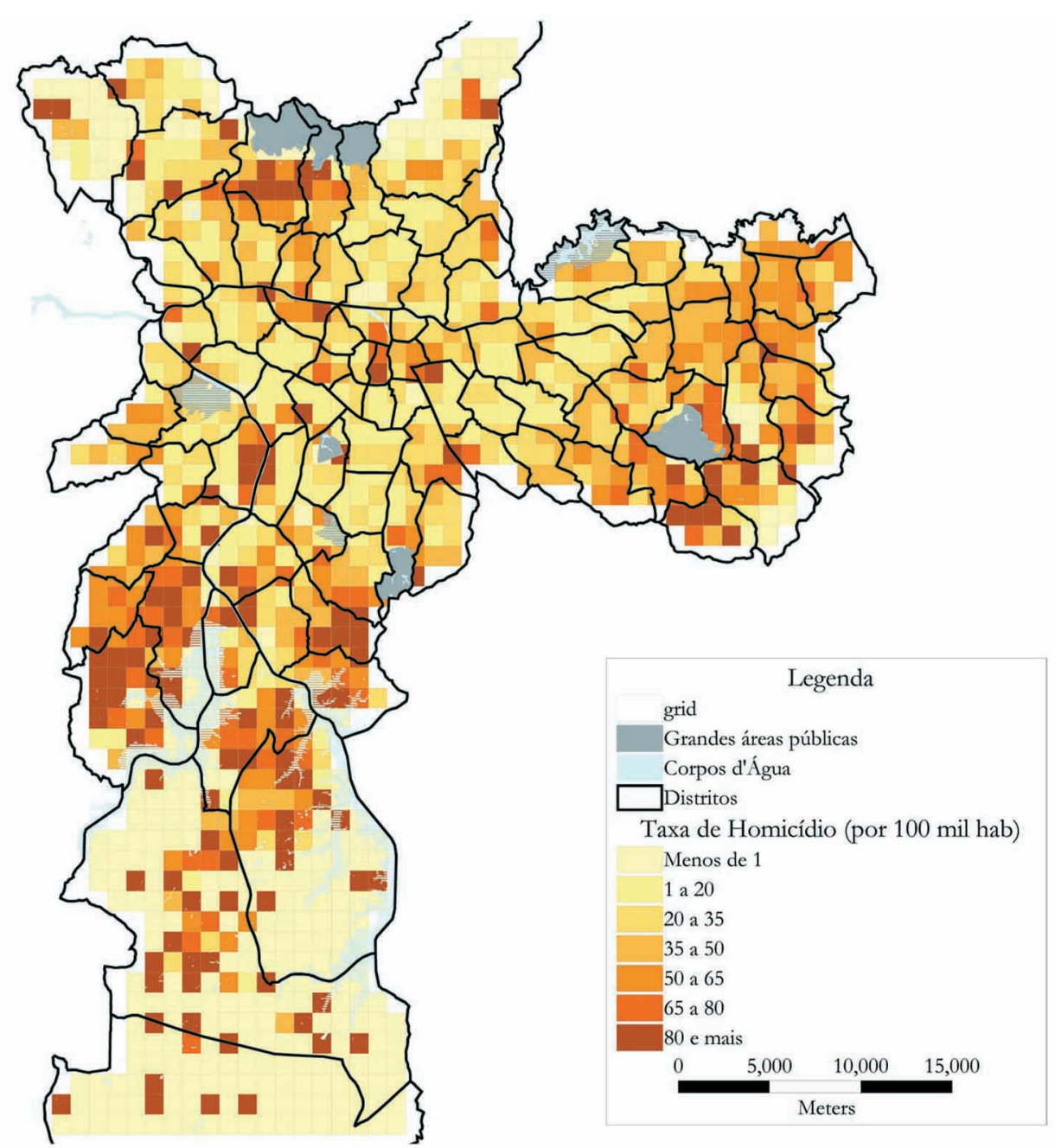

Fonte: Fundação Seade, 1998-2000.

M apa 3 - Taxas de H omicídio por grid Considerando o Local de Residência das Vítimas. 
O utra área de política pública em que a distribuição espacial da oferta/ demanda é muito importante é a educação básica. I sso acontece porque o custo (não apenas financeiro, mas também social) dos deslocamentos espaciais tende a ser muito al to para pessoas muito jovens, especialmente entre os pobres. E mbora - Estado esteja obrigado pela Constituição a oferecer educação para todas as crianças entre sete e catorze anos de idade, existem poucos mecanismos legais e administrativos que especifiquem que as dependências destinadas à educação pública devam ficar a determinada distância da casa da criança. Em vista disso, pelo menos nas grandes regiões metropolitanas como São Paulo, onde o acesso a essa política é quase universal, as condições e a qualidade da escola são as questões mais importantes para a melhoria da educação.

Além disso, mesmo no contexto das escolas públicas, os indicadores educacionais podem variar significativamente em virtude de diferentes elementos como a escolaridade da família, a renda e as condições da escola. Embora não tenhamos dados para aprofundar essa questão no momento, apresentamos, na Tabela 5, informações sobre o desempenho médio dos alunos (de 5 a e 7 ạ séries) da rede estadual de ensino nas provas de Língua Portuguesa do Saresp, de acordo com a localização das escolas nos diferentes quintis do indicador de privação detalhado anteriormente.

Tabela 5: D esempenho M édio (em \%) em Língua Portuguesa segundo Q uintis do Indicador de Privação. Escolas Estaduais do M unicípio de São Paulo, 2001.

\begin{tabular}{|c|c|c|}
\hline Quintis & 5a série & 7a série \\
\hline 1 & 48,9 & 47,3 \\
2 & 44,6 & 44,7 \\
3 & 44,2 & 44,3 \\
4 & 43,8 & 43,8 \\
5 & 42,9 & 43,4 \\
Total & 44,7 & 44,5 \\
\hline
\end{tabular}

Fonte: Secretaria de E ducação do Estado de São Paulo (Saresp - Sistema de Avaliação e R endimento Escolar).

O bservação: A identificação de onde cada escola se localizava em cada grupo de setores foi possível por meio do uso do SI G. N ão incluímos nessa média as assim chamadas "classes noturnas".

Pode-se observar que as melhores médias estão presentes nas escolas localizadas no quintil 1, ao passo que as piores estão no quintil $5^{25}$. Em geral, esses dados parecem variar de forma semelhante aos anteriormente descritos, mas a evidência mais importante mostrada na Tabela 5 é de que a variação é bastante moderada. Em parte, isto se deve ao fato de que as famílias ricas não colocam suas crianças em escolas públicas. E ntretanto, outros elementos relacionados aos padrões espaciais de distribuição das notas em Língua Portuguesa - de forma 
semelhante aos observados em relação aos homicídios - também estão presentes, enfatizando mais uma vez o perigo de desconsiderarmos os detalhes que se escondem por trás das grandes números e dos valores médios.

Como se pode ver no $M$ apa 4, a distribuição de notas muito baixas não é homogênea nas várias periferias ${ }^{26}$. Podem ser observadas mais uma vez significativas concentrações de notas baixas em Língua Portuguesa no J ardim Ângela (sudoeste), bem como em um aglomerado relevante localizado na área leste da cidade de São Paulo (I taim Paulista). Também é possível notar alguns bairros pobres ao norte e regiões no sudeste que apresentam notas próximas ou acima da média.

Portanto, parece bastante claro que um modelo dual centro-periferia também não explica as diferenças observadas no desempenho em provas de Língua Portuguesa nas periferias. E sses resultados são bastante semel hantes aos apresentados antes para índices de homicídios, embora as localizações não coincidam perfeitamente ${ }^{27}$. No momento, não temos dados suficientes para interpretar esses fenômenos, mas é possível argumentar que a segregação não pode ser plenamente entendida sem o estudo desses " pontos críticos" de especial concentração de elementos negativos e sem que incorporemos em nosso instrumental conceitual a heterogeneidade da periferia.

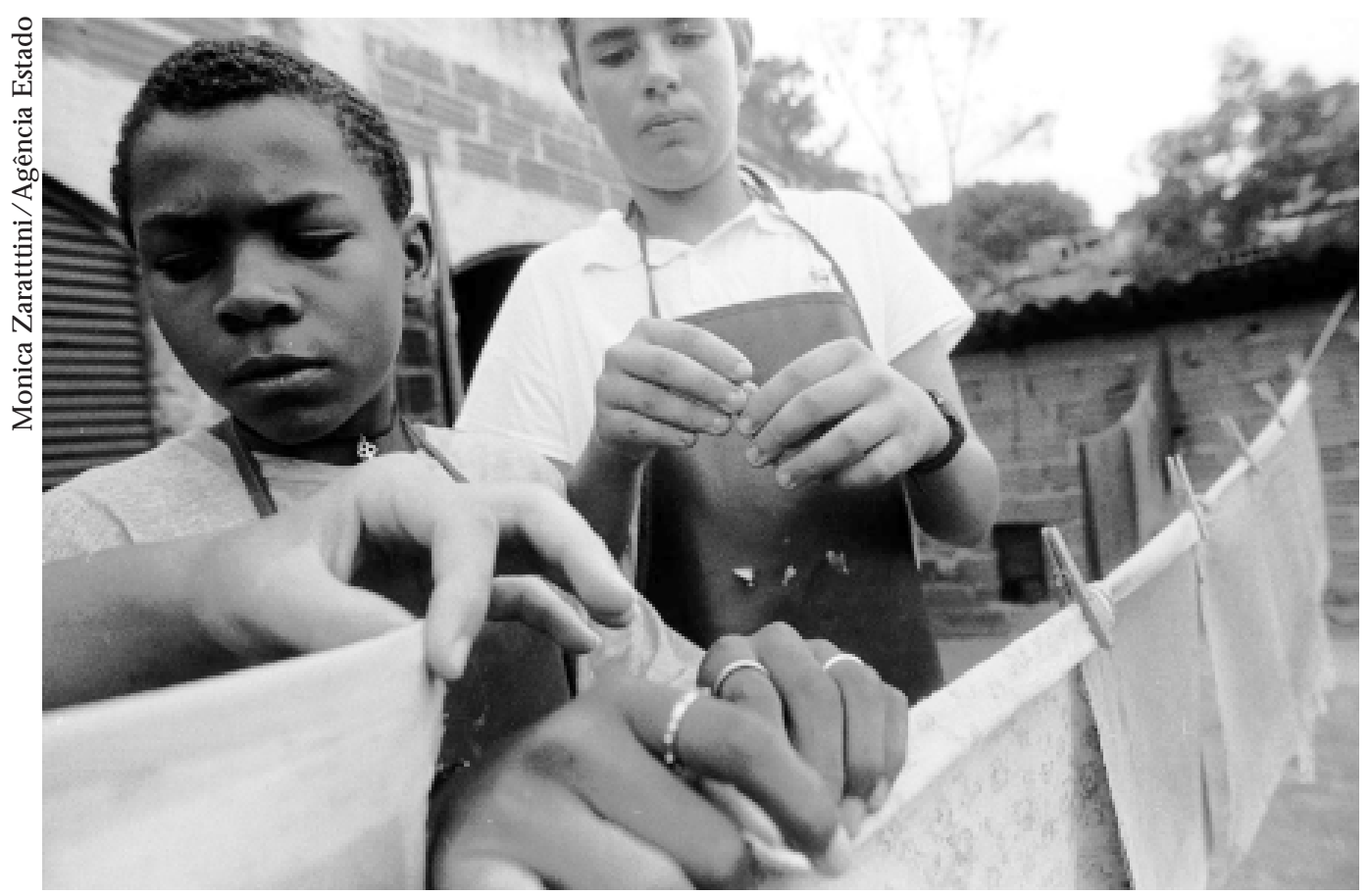

M eninos da favela Monte A zul (zona Sul) aprendem a reciclar papel 
H AROLDO Da Gama Torres et al.

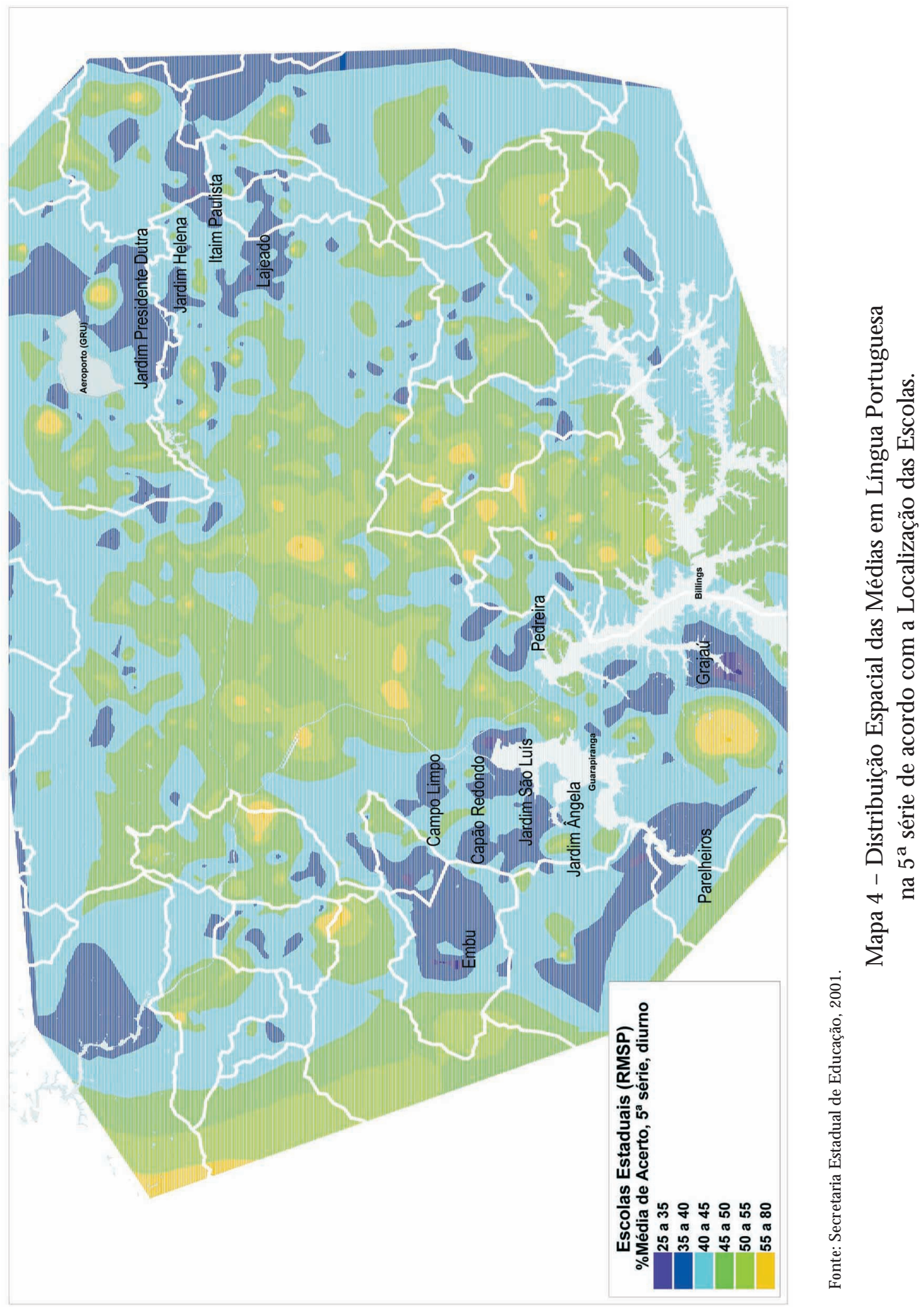




\section{C onclusão}

$\mathrm{N}$ este artigo apresentamos os resultados de um trabalho em andamento que envolve a delimitação de grupos sociais vulneráveis e incorpora as múltiplas dimensões da pobreza. D esenvolvemos uma análise fatorial utilizando como input os indicadores sociais do C enso de 2000 por setores censitários. A análise indicou a existência de dois diferentes fatores, que interpretamos como um índice de privação e um índice do ciclo de vida familiar. A distribuição do índice de privação no espaço mostrou, numa visão muito geral, uma estrutura centro-periferia com uma curva negativa dos indicadores sociais à medida que se vai do centro para as periferias. Entretanto, a distribuição do índice no espaço apresenta uma significativa heterogeneidade na configuração espacial da metrópole, especialmente nas áreas periféricas. Os mapas mostram também a existência de alguns importantes subcentros de grupos sociais ricos local izados fora do chamado centro expandido.

Também encontramos uma significativa diversidade dentro das periferias, nas quais diferentes grupos estão sujeitos a condições de vida muito diferentes, por exemplo, no que se refere aos índices de homicídio e desempenho escolar. Em alguns espaços da periferia, há uma intensa concentração de indicadores negativos, que sugerem a existência de "pontos críticos" com condições sociais precárias. Todos esses dados indicam que a distribuição de grupos sociais na metrópole é muito mais complexa e heterogênea do que geralmente considera a literatura, que tende a homogeneizar as periferias, com importantes conseqüências para as políticas públicas.

É muito importante entender que, se a segregação pode ser gerada por ações governamentais, também é verdade que o Estado tem condições de mitigar esse efeito, criando políticas de integração social e espacial. Aparentemente, existem dois modos diferentes de encarar o problema. 0 primeiro seria misturar as pessoas, forçando os grupos sociais mais pobres e mais ricos a conviver e interagir mais intensamente (Briggs, 2001). A segunda seria melhorar as condições urbanas das áreas mais pobres, elevando-as a um padrão mais próximo das habitadas pelos mais ricos. O bviamente, as duas abordagens podem, enormalmente são, associadas. Considerando-se essas estratégias, poderíamos classificar as políticas governamentais que têm impacto sobre o espaço urbano em dois grupos principais:

- políticas governamentaisrelativasao espaço construído - nesse grupo, estão incluídas as políticas de regulamentação urbana, bem como os investimentos em infra-estrutura urbana nas partes da cidade habitadas pelos pobres. As políticas de regulação urbana podem incentivar processos de mobilidade espacial que operam na direção oposta dos padrões de segregação, misturando as pessoas; também podem dirigir as futuras ações governamentais para determinadas regiões das cidades que são consideradas prioridades sociais, melhorando as condições das periferias, favelas e cortiços e, assim, reduzindo a diferença entre os grupos sociais (Fernandes, 1998) ${ }^{28}$; 
- políticas sociais "espacialmente organizadas" - as políticas governamentais podem também mitigar a segregação urbana por meio do grupo tradicional de políticas sociais. Esse conjunto de políticas públicas inclui, no mínimo, educação, saúde, assistência social, esportes, cultura e lazer, criando e transformando o espaço social, pois a localização de seus equipamentos (e suas diferentes características inserções no espaço) definem as condições de acesso dos vários grupos so ciais que habitam na cidade.

Essas políticas são especialmente importantes por causa da invisibilidade dos mais pobres entre os pobres (Torres, 2001), não apenas porque eles têm maiores problemas para se organizar e vocalizar as suas demandas, mas também porque as rotinas administrativas das agências estatais nunca os consideram de forma diferenciada. I sso pode acontecer em virtude do preconceito social dos técnicos ( $M$ arques, 2000), mas na maioria dos casos os motivos estão ligados à implementação das próprias políticas públicas, pois mesmo a informação sobre quem deve e quem não deve receber assistência é influenciada por uma definição prévia do que a assistência deve ser. Boa parte da solução desses problemas depende muito do conhecimento da exata distribuição da oferta de serviços, bem como de sua demanda em cada área. Esse conhecimento, em uma grande área urbana, pode ser disponibilizado por um SIG ou por tecnologias semelhantes. $N$ esse sentido, pretendemos incorporar, na próxima fase do projeto, informações sobre outras políticas públicas como saúde, educação, assistência social e esportes, bem como outros aspectos do ambiente construído - a pobreza e as diversas formas de legalidade/ ilegalidade da ocupação (favelas e loteamentos irregulares e clandestinos).

N otas

1 Veja www.centrodametropole.org.br

2 A noção de periferia, portanto, opõe-se sociologicamente (e também geograficamente) aos subúrbios norte-americanos produzidos desde a década de 1940, mas pode ser equivalente a eles em sua geometria no que diz respeito à forma urbana.

3 As referências sobre esses assentamentos são muitas. Veja, p.ex., C hinneli (1980), Santos (1982) e Bonduki e Rolnik (1982); sobre a autoconstrução, veja M aricato (1982).

40 maior diferencial das favelas é que elas podem, algumas vezes, estar geograficamente mais próximas de vizinhanças ricas. Além disso, a terra em que 0 assentamento se localiza não pertence a seus habitantes, envolvendo sempre alguma forma de invasão de terras. N o Rio de Janeiro, em Salvador e Recife, esse tipo de solução de moradia predominou antes da década de 1950 (Brandão 1978 e Egler, 1986) e continuou a ser importante tanto em termos absolutos quanto relativos, embora os assentamentos irregulares tenham se tornado cada vez mais significativos (Santos, 1975). Em São Paulo, a solução de moradia predominante para os pobres em 1950 eram os cortiços, em geral casas antigas e arruinadas ocupadas coletivamente por muitas famílias, em que os "cômodos molhados" - banheiro e cozinha - são utilizados também coletivamente (Kowarick e Ant, 1988). M ais para a frente, os loteamentos irregulares 
passaram a predominar (Sampaio, 1994); muito recentemente, as favelas tiveram sua presença aumentada.

5 Ao mesmo tempo, os cortiços aparentemente retornaram. Os dois processos contribuíram para difundir a presença de grupos de pobreza em diferentes partes das cidades, aumentando a heterogeneidade dos espaços (Kowarick, 2002).

6 Veja, por exemplo, vários artigos em Kowarick (1988).

7 N o Brasil, o aparato institucional criado pelo regime militar nas décadas de 1960 e 1970 deixou uma forte herança. N ovas agências nacionais por setor de política pública foram estabelecidas durante o regime e várias novas agências estaduais foram anexadas a agências federais que estabeleciam arranjos de financiamento e rotinas administrativas (D raibe, 1989 e Fagnani, 1997). E mbora na década de 1990 esses sistemas tenham sido transformados pela extinção de agências federais ou equações financeiras responsáveis por esses arranjos (Arretche, 2000), as agências locais continuaram a existir. Como conseqüência disso, continuou a expansão dos serviços para a periferia, mesmo que algumas vezes ela tenha seguido critérios ou trajetos diversos. Essa idéia de inércia institucional é intensamente desenvolvida pelo novo institucionalismo em Ciência Política (Skocpol, 1992).

$8 \mathrm{~A}$ principal diferença entre os antigos e novos padrões de pobreza urbana nessas cidades parece ser o grau de segregação e as reduzidas oportunidades de mobilidade social experimentadas pelos grupos sociais das áreas mais segregadas (Wilson, 1990).

9 É interessante notar que as conseqüências da segregação não são necessariamente consideradas negativas pela literatura da área, mesmo no que diz respeito à segregação étnica. Portes e Stepick (1993) demonstram que a transformação pela qual passou M iami nas últimas décadas, bem como a mudança da posição social de determinadas comunidades latino-americanas dentro da cidade (principalmente as cubanas) foram possíveis por meio da separação e da coesão interna. Essa constatação nos leva ao debate sobre a produção de capital social nas comunidades urbanas. Como observou Briggs (2001), entretanto, o isolamento pode forjar a cooperação, mas também pode gerar corrupção política, crime e violência.

10 Para alguns autores (Santos e Bronstein, 1978), isso seria a reprodução, em termos espaciais, da altamente concentrada distribuição de renda brasileira, levando a vários problemas sociais, inclusive à violência (Ferreira, 2002 e M aricato, 1996).

11 A pesar de sua grande importância, esses fenômenos não foram ad equadamente considerados pela literatura, em parte por causa de problemas metodológicos. 0 cerne da discussão está na heterogeneidade das periferias, reforçada por recentes processos de transformação. D e fato, a ações governamentais mel horaram a média dos indicadores sociais dessas regiões da cidade. Portanto, a visibilidade de padrões diferentes de pobreza, bem como da hiperperiferia, depende da possibilidade do desenvolvimento de análises muito detalhadas, tais como a possibilitada pelos sistemas de informações geográficas ( $\mathrm{SIGs}$ ).

12 N esses países, a economia seria necessariamente organizada em torno de salários muito baixos (M aricato, 1987) e da falta de serviços públicos, o que levaria ao surgimento de processos de espoliação urbana (Kowarick, 1979; Kowarick e Campanário, 1988). Essa tradição renovou-se recentemente com trabalhos como os de Kowarick (2002), Taschner (2000), Ribeiro e Telles (2000) e L ago (2000). 
130 influência das análises da sociologia urbana francesa feitas por autores como Topalov (1974) e Lipietz (1974) é explícita nesse caso.

14 Esse mecanismo, pelo menos no Brasil, parece ser mais comum em governos de direita do que em administrações ligadas à esquerda (M arques e Bichir, 2002). U m segundo mecanismo, muito mais explícito, seria a expulsão de grupos sociais de baixa renda de algumas partes da cidade pelo Estado. I sso acontece normal mente nas cidades mais importantes do Brasil, pelo processo de remoção de favelas (Valladares, 1978 e Fix, 2001) e, às vezes, em virtude da expansão de obras públicas, isto é, projetos importantes de infra-estrutura (Santos, 1981 e Fix, 2001). Em São Paulo, a construção de vias junto a cursos d'água envolve mecanismos de remoção bastante poderosos, pois muitas favelas se localizam nessas áreas. D uas das mais importantes avenidas construídas em São Paulo na última década (Águas E spraiadas e J acu-Pêssego) são exemplos significativos desse processo (F ix, 2001 e M arques e Bichir, 2002).

$15 \mathrm{O}$ Índice de D esenvolvimento H umano (IDH ) pode ser considerado uma estratégia para abordar esse problema em comparações internacionais de pobreza. Veja N ussbaun e Sen (1998) e U N D P (2000).

16 A análise fatorial também indicou a presença de um indicador de ciclo de família, mas neste artigo apresentamos apenas os resultados do indicador de privação. Além disso, os diferentes setores censitários foram agrupados e classificados de acordo com suas características sociodemográficas, a fim de permitir um entendimento abrangente da paisagem urbana e na definição de prioridades para a ação pública visando ao abrandamento da pobreza. Para fazer isso, adotamosum modelo de análise de aglomerados (cluster analysis) que nos permitiu identificar, com base na análise fatorial anterior, áreas com características particulares tais como: alta concentração de idosos e alto nível de pobreza. Esses resultados não são apresentados no presente artigo.

17 Veja a Seção 4.

18 Além disso, infelizmente não conseguimos trabalhar com a variável coleta de esgoto (88\% de cobertura), em razão de problemas com a base de dados original fornecida pelo IBGE. O utras variáveis, como a condição de propriedade da terra, também são problemáticas, porque existe uma grande variação no que se declara so bre a condição do uso da terra em áreas invadidas.

19 A exclusão de variáveis deveu-se à sua baixa comunalidade (abaixo de 0,40 ) e à sua pouca contribuição para a melhoria da explicação da variância total desse conjunto de dados (Dillon e G oldstein, 1984).

20 Após a transformação Varimax, constatamos que o fator 1 (dimensão da privação) explica 39,7\% dessa variância, e que o fator 2 (dimensão do ciclo familiar) explica $37 \%$ A estatística Kayser-M eyer-O Ikin ( $M$ easure of Sampling A dequacy) obtida neste modelo foi de 0,869 , indicando adequação do modelo para explicar e quantificar o grau de inter-relações das variáveis ( $H$ air, 1998). Também foi realizada uma análise fatorial abrangendo apenas o município de São Paulo (13 mil setores) e os resultados foram iguais aos obtidos para a Região M etropolitana.

$21 \mathrm{Em}$ sociedades como a brasileira, a presença de mulheres chefes é interpretada comumente como um indicativo da presença de apenas um provedor adulto, não estando presente 0 casal. 
$22 N$ ão é mera coincidência que esses grupos - chamados na literatura sobre pesquisa de mercado de classes A e B - sejam os principais alvos de empresas nacionais e multinacionais do Brasil. Eles representam mais de $55 \%$ de todos os gastos de consumidores no Brasil (Fauze, 2001).

230 índice de homicídios por grid foi produzido pelo cruzamento de dados (overlay) da distribuição de pontos de homicídios (numerador) com os dados populacionais advindos dos setores censitários (denominador). A técnica de cruzamento de dados utilizada aqui é a que está disponível no programa M aptitude, 4.5. É muito provável que os valores apresentados aqui estejam abaixo do real, pois existem atestados de óbito sem registro de endereço, bem como mortes não registradas. Além disso, não conseguimos encontrar o endereço de 351 atestados de óbito com declaração de endereço. 0 índice médio de homicídios que pudemos apurar foi de 43,7 por 100 mil (1998-2000), ao passo que os valores oficiais da Secretaria Pública de Segurança apontam para índices de 51,2 em 2000 (veja www.segurança.sp.gov.br). É bem possível que o viés criado por esses problemas implique uma estimativa ainda mais abaixo do real do índice de homicídios nas áreas e nos grupos sociais mais pobres. Se isso se verificar, a constatação não afetará a interpretação fornecida aqui, mas apenas reforçará os padrões enfatizados.

24 E mbora não seja o caso de produzir aqui uma interpretação sobre as causas de variação do índice de homicídios em diferentes áreas da cidade, é possível argumentar que outras variáveis, tais como a proporção de adolescentes na população, também podem estar correlacionados com essa variável (ver Tabela 4). 0 quintil 5, que apresenta o mais alto índice de homicídios, também é o mais pobre e deve ser aquele que apresenta a maior proporção de adolescentes na população total.

25 Surgem aqui alguns problemas metodológicos. Como não existem distritos escolares no Brasil, não se pode supor que as crianças necessariamente estudem no mesmo lugar em que moram. Além disso, as famílias mais ricas não colocam suas crianças em escolas públicas de ensino básico, o que significa que essas famílias não usam necessariamente as escolas públicas localizadas nas áreas mais ricas. M esmo levando-se em consideração esses problemas, os diferenciais de notas para cada quintil são moderadamente significativos, em especial na 5 a série.

26 Esse mapa é uma tentativa de representar a informação sobre o desempenho em Língua Portuguesa como um mapa altimétrico. Supõe-se que cada escola estadual ( 1.175 com informações sobre notas) representa um ponto em uma amostra de "altitudes" que é, em geral, utilizada para produzir mapas de topografia.

27 Por exemplo, na zona leste do município de São Paulo, a tendência é haver índices mais altos de homicídios na parte sul, ao passo que índices de notas mais baixas predominam na parte norte daquela região.

$280 \mathrm{~s}$ investimentos estatais em periferias e áreas habitadas por pessoas pobres têm 0 efeito óbvio de melhorar as condições de vida nessas áreas, reduzindo, portanto, as diferenças sociais. Em todos os casos, porém, existe o risco de desencadear processos de mobilidade espacial que operam na mesma direção da segregação, visto que 0 aumento do valor do solo causado pelas melhorias pode resultar na expulsão dos pobres e em sua substituição por grupos sociais mais ricos. 
R eferências bibliográficas

ABRAM O , P. (1994). Lemarché, I'ordre désordreet la coordination spatiale. Paris, EH ESS, tese de doutorado.

ABREU , M . (1987). Evolução urbana do R io deJ aneiro. Rio de Janeiro, I plamRio/ Zahar.

ALESP (2000). Cadernos do Fórum São Paulo: Século XXI. São Paulo, Alesp.

ARRETCHE, M (2000). Estado federativo e políticas sociais. Rio de Janeiro, Revan.

BERCOVICH , A. M.; M ADEIRA, F. R. eTORRES, H. G. (1998). "D escontinuidades demográficas". In: Seade, 20 anos no ano 2000: estudos soci odemográfi cos sobre a juventude paulista. São Paulo, Seade, pp. 2-13.

BECKER, G. (1988). "Family Economics and M acro Behavior". A merican Economic R eview, vol. 78, n. 1, pp. 1-13.

BLAIKIE, P. et alii (1994). A t R isk: N atural H azards, People'sVulnerability, and Disasters. London, Routledge.

BO N D U KI, N . e RO LN IK, R. (1982). "Periferia da Grande São Paulo: reprodução do espaço como expediente de reprodução da força de trabalho". In: M ARICATO, E. (org.). A produção capitalista da casa (e da cidade) do Brasil industrial. São Paulo, Alfa-Ô mega. pp. 117-154.

BRAN D ÃO , M . (1978). "O rigens da expansão periférica em Salvador". Planejamento, vol. 6 (2), pp. 155-171.

BRASI LEIRO, A. (org.) (1976). R egião M etropolitana do R io de J aneiro: ser vi ços de inter esse comum. Brasília, I pea/ I bam.

BRIGGS, Xavier S. (2001). "Ties that Bind, Bridge, and Constrain: Social Capital and Segregation in American M etropolis". Trabalho apresentado no "I nternational Seminar of Segregation and the City". Cambridge, Lincoln Institute of L and Polic. www.lincolninst.edu.

BU SSAB, W. O . et alii. (1990). Introdução à análisedeagrupamentos. São Paulo, Associação Brasileira de E statística ( 9 Simpósio Brasileiro de Probabilidade e Estatística).

CALDEIRA, Teresa, P. (2000). Cidade demuros. São Paulo, Edusp/ Editora 34.

CARDIA, N . (1999). "O s impactos da exposição à violência: aceitação da violência ou horror continuado: 0 caso deSão Paulo". Trabalho apresentado no encontro "Culture, Citizenship, and U rban Violence", em Cuernavaca, M éxico.

CARDIA, N. (2000). U rban Violence in São Paulo. Washington, D.C., Woodrow Wilson International Center for Scholars (Comparative U rban Studies O ccasional Papers Series, 33), www.nev.prp.usp.br .

CEPAL (2002). Panorama social da A mérica Latina 2000-2001. Santiago, Cepal.

CH INELLI, F. (1980). "O s loteamentos da periferia". In: VALLADARES, L. do P. (org.). H abitação em questão. Rio de J aneiro, Zahar, pp. 49-68.

CU N H A, J. M. P. e TO RRES, H . G . (1994). "Estimativas populacionais para pequenas áreas a partir do uso de fotografia aérea. U ma aplicação para o município de Campinas". A naisdo IX Encontro $\mathrm{N}$ acional deEstudosPopulacionais. Belo $\mathrm{H}$ orizonte, Abep, vol. 1, pp. 163-172.

DAVIS, M. (1990). City of Quartz. Los Angeles, Vintage/ Random H ouse. 
DEBRAJ , R. (1998). D evelopment E conomics. N ova J ersey, Princeton U niversity Press.

DILLON, W. R. e GOLDSTEIN, M. (1984). Multivariate A nalysis. M ethods and A pplications. N ew York, John Wiley \& Sons.

D'IN CAO , M . (1976). O bóia-fria - acumulação emiséria. Rio de J aneiro, Paz e Terra.

DRAIBE, S. (1989). "O WelfareStateno Brasil: características e perspectivas". Ciências SociaisH oje Rio de Janeiro, Anpocs/ Ed. Rio Fundo.

EGLER, T. (1986). O chão da nossa casa: a produção da habitação em R ecife São Paulo, U SP, tese de doutorado.

ERIKSO N, R. (1998). “D escripciones de la D esigualdad: E I Enfoque Sueco de la I nvestigación sobre el Bienestar". In: N U SSBAU N, M. eSE N A. (compiladores). La Calidad deVida. M éxico, Fondo de Cultura E conómica e The U nited $\mathrm{N}$ ations $\mathrm{U}$ niversity.

EVAN S, TOM P. eM O RAN , E. F. (2002). "Spatial Integration of Social and Biophysical Factors Related to Land Cover Change". In: LUTZ, W.; PRSKAWETZ, A. e SAN DERSO N W. C. Population and Environment: M ethods of Analysis. Population and D evelopment R eview, a Supplement to vol. 28, pp. 165-186.

FAGN AN I, E. (1997). "Política social e pactos conservadores no Brasil: 1964/ 1992". Economia e Sociedade, n. 8, pp. 183-238.

FAI N STEIN, S.; GORD O N, L. eH ARLOE, M. (1992). Divided Cities N ew York and London in the Contemporary World. London, Blackwell.

FAU ZE, N . (2001). Pesquisa de marketing. São Paulo, Atlas.

FER N AN DES, E. (1998). Direito urbanístico. São Paulo, Livraria D el Rey.

FERREIRA, M . I. (2002). "A Ronda da pobreza: violência e morte na solidariedade". N ovos Estudos Cebrap, n. 63, pp. 167-178.

FIX, M. (2001). Parceiros da exclusão. São Paulo, Boitempo.

FOTHERINGHAN, S. e ROGERSON, P. (org.) (1994). Spatial A nalysis and GIS. London, Taylor and Francis, pp. 121-145.

GILBERT, A. eGLU GER, J. (1992). Cities, Poverty, and D evelopment. O xford, O xford U niversity Press.

GLUGER, J. (org.) (1988). The U rbanization of the Third World. Oxford, Oxford $U$ niversity Press.

GO ODCH ILD, M. F.; STEYAERT, L. T. ePARK, B. O . (org.) (1996). Environmental M odeling: Progressand R esearch I ssues. Fort Collings, GIS World Books, pp. 191-195.

GOSS, J. (1995). "We Know Who You are and We Know Where You Live: The I nstrumental Rationality of Geodemographic Systems". Economic G eography, vol. 71, n. 2.

HAIR, J. F; ANDERSO N, R. E.; TATHAN, R. L. e BLACK, W. C. (1998). 5a ed. $M$ ultivariate $D$ ata A nalysis. $\mathrm{N}$ ew J ersey, Prentice $\mathrm{H}$ all.

H ÄU SSERM AN N , H . eKAZEPOV, Y. (1996). "U rban Poverty in Germany: A Comparative Aanalysis of the Profile of the Poor in Stuttgart and B erlin". In: M IN GIONE, E. U rban Poverty and the U nderclass L ondon, Blackwell, pp. 343-369.

H EWITT III, M . J. (1993). "Risk and H azard M odeling". I n: GOO D CH ILD, M. F.; PARK, B. O. e STEYAERT, L. T. (org.) Environmental Modeling with GIS. N ew York, O xford U niversity Press, p. 317. 
H U XH O LD, W. E. (1991). A n Introduction to U rban Geographic I nformation Systems. L ondon, O xford U niversity Press.

JEN CKS, C. (1993). H eterotopolis: Los A ngeles, R iots and the Strange Beauty of $\mathrm{H}$ eteroarchi tecture. London, A cademy E ditors.

J OH NSON, A. I.; PETTERSON, C. B. e FULTON, J. L. (1992). Geographic Informati on Systemsand M apping: Practicesand Standards. Philadelphia, ASTM .

KOWARICK, L. (1979). A espoliação urbana. Rio de Janeiro, Paz e Terra.

(1982). "O preço do progresso: crescimento econômico, pauperização e espoliação urbana". In: M O ISÉS, J. A. (org.) Cidade, povo e poder. Rio de J aneiro, Paz e Terra/ Cedec, pp. 30-48.

(ed.). (1988) A slutas sociaise a cidade. Rio de J aneiro, Paz e Terra.

(2002). "Viver em risco - sobre a vulnerabilidade do Brasil urbano". N ovos Estudos Cebrap, n. 63, pp. 9-30.

(1995). "Investigação urbana e sociedade". I n: REIS, E.; ALM EID A, M. H. e FRY, P. Pluralismo, espaço social e pesquisa. São Paulo, H ucitec/ Anpocs.

KOWARICK L. e ANT, C. (1988). Cem anos de promiscuidade - o cortiço da cidade de São Paulo. In: KOWARICH , L. A slutas sociaise a cidade. Rio de Janeiro, Paz e Terra, pp. 49-74.

KOWARICK, L. e CAM PAN ÁRIO , M . (1993). "São Paulo: do milagre à crise". Lua N ova, n. 28/ 29, pp.239-264.

KU M AR, A. K. Shiva. (1999). Short Term Changes in D evelopment: Tracking Inputs, A ssessing Efforts, M easuring Outcomes. D elhi, trabalho para discussão.

LAGO, L. (2000). D es gualdades e segregação na metrópole. Rio de J aneiro, Revan.

LIPIETZ, A. (1974). LeTribut Foncier U rbain. Paris, Ed. M aspero.

LIPSET, S. (1959). "Some Social R equisites of D emocracy: D evelopment and Political L egitimacy". The A merican Political ScienceR eview, n. 53, pp. 69-105.

LO GAN , J. (2000). "Still a G lobal City: The Racial and Ethnic Segmentation of N ew York". In: M ARCU SE, P. e KEM PEN, R. Globalizing Cities. A N ew Spatial Order? London, Blackwell, pp.158-185.

LOGAN, J.; TAYLOR-GOOBY, P. e REUTER, M. (1992). "Poverty and Income I nequality". In: FAINSTEIN , S.; GORDON, I. e H ARLOE, M. Divided Cities N ew York and London in the Contemporary World. London, Blackwell, pp. 129-150.

M ARCU SE, P. (1996). "Space and Race in the Post-fordist City: The O utcast G hetto and Advanced H omelessness in the U nited States Today". I n: M I N GI O N E, E. U rban Poverty and the U nderclass, London, Blackwell, pp. 176-216.

M ARICATO ,E. (1982). "Autoconstrução, a arquitetura possível" . In: M ARICATO , Ermínia (org.). A produção da casa (eda cidade) no Brasil industrial. São Paulo, Alfa-Ô mega.

(1986). "Labour Force and Building Industry in Brazil: Accumulation and Super Exploitation". Trabalho apresentado no seminário "The Production of the Built Environment". London, Bartlett International School.

(1996). M etrópolena periferia do capitalismo: ilegalidade, desigualdade eviolência. São Paulo, H ucitec. 
M ARQ U ES, E. (2000). Estado e redes sociais. per meabilidade e coesão nas políticas de infra-estrutura urbana no R io de Janeiro. Rio de Janeiro, Revan.

MARQUES, E. e BICHIR, R. (2002). "I nvestimentos públicos, infra-estrutura urbana e produção da periferia em São Paulo". R evista Espaço e D ebates, n. 42, pp. 9-30.

(2001). "Estado e espaço urbano - Revisitando criticamente as explicações correntes sobre as políticas estatais urbanas: Padrões espaciais de ação estatal na infra-estrutura urbana em São Paulo 1978/ 1998". R evista de Soci ologia e Política, n. 15, pp. 9-30.

M ARQ U ES, E. e BITAR, S. (2002). “E spaço e grupos sociais na metrópole paulistana”. N ovos Estudos Cebrap, n. 64, pp. 123-131.

M ARTIN E, George; H AKKERT, Ralph e GU ZM AN , José M iguel (2000). “Population and Development Strategies: Responding to $\mathrm{N}$ ew Challenges". M éxico, U NFPA Country Support Team for Latin A merican and The Caribbean, www.eat.org.mx .

MERRICK, Thomas W. (2002). "Population and Poverty: New View and Old Controversy". I nternational Family Planning Perspectives, vol. 28, n. 1, pp. 41-45.

M IN GI O N E, Enzo (1999). "U rban Poverty in the Advanced I ndustrial World: Concepts, Analysis and D ebates". I n: M I N G I O NE, Enzo (org.). U rban Pover tyand theU nderclass N ew York, Blackwell, pp. 30-40.

M ORAD, M . eBOYT, C. (1994). "Spatially Referenced D ata of Growing I mportance". Planning Quarterly, dez. 1994.

M ORRISO N, D. F. (1990). M ultivariateStatistical M ethods. N ew York, M cG raw H ill.

NERI, J. (2002). U m século de política para poucos: o zon eamento paulistano 1886-1996. São Paulo, FAU -U SP, tese de doutorado.

N U SSBAU N, M . e SEN , A. (1998). La Calidad deVida (introdução). M éxico, Fondo de Cultura E conómica e The $U$ nited $N$ ations $U$ niversity.

OLIVEN, R. (1997). U rbanization and Social Change in Brazil: A Case Study of Por to A legre. London School of E conomics and Political Science, tese de doutorado.

PERILLO , S. e PERDIGÃO, M . (1998). "Cenários migratórios recentes em São PauIo". Trabalho apresentado no XI Encontro N acional da Associação Brasileira de Estudos Populacionais - Abep.

PORTES, A. e STEPICK, E. (1993). City on the Edge: The Transormation of Miami. Los Angeles, The U niversity of California Press.

PRETECEILLE, E. e VALLAD ARES, L. (1999). "Favelas no plural". C axambu; trabaIho apresentado no XXIII Encontro da Associação N acional de Pós-Graduação e Pesquisa em Ciências Sociais - Anpocs.

REJESKI, D. (1993). "GIS and Risk: A Three-Culture Problem". In: GO O D CH ILD, M. R.; PARK, B. O . e STEYAERT, L. T. (orgs.). Environmental M odeling with GIS. N ew York, O xford U niversity Press, pp. 318-331.

RIBEIRO, L. (1997). D os cortiços aos condomíni os fechados as formas de produção da moradia na cidade do R io de J aneiro. R io de J aneiro, Civilização Brasileira.

RIBEIRO, L. C. e TELLES, E. (2000). "Rio de Janeiro: Emerging Dualization in a $H$ istorically U nequal City". In: M ARCU SE, P. e KEM PEN, R. Globalizing Cities A $\mathrm{N}$ ew Spatial Order? London, Blackwell. 
RIEFF, D. (1991). LosA ngeles Capital of theThird World. N ew York, Touchstone Books.

ROCH A, Sônia (1996). "Renda e pobreza: os impactos do Plano Real". I pea, Textos para D iscussão, n. 439. Rio de J aneiro, www.ipea.gov.br .

RO L N IK, R. (1997). A cidadeea lei : legi sação, política urbana eterritóriosna cidadede São Paulo. São Paulo, N obel/ Fapesp.

RU BAL CAVA, R. M . e O RDAZ, J. C. (1999). “Población Prioritária en Z onas M arginadas". In: GARZA, Gustavo (org.). A tlas D emográfico de M éxico. M éxico, ConapoProgresa, pp. 39-83.

SAM PAI O, M . R. (1994). "O papel da iniciativa privada na formação da periferia paulistana". Espaço eD ebates, n. 37, pp. 19-33.

SAN TOS, C. (1975). Voltando a pensar em favelaspor causa dasperiferias. Rio de Janeiro, mimeo.

(1980). "Velhas novidades nos modos de urbanização brasileiros". In: VALLADARES, L. (org.). H abitação em quetão. Rio de J aneiro, Z ahar.

(1981). M ovimentos urbanosno R io de Janeiro. Rio de J aneiro, Zahar.

(1982). Processo de crescimento e ocupação da periferia. Rio de Janeiro, IBAM / CPU .

(1985). "Loteamentos na periferia metropolitana". R evista de Adminis tração Municipal, vol. 32, n. 174, pp. 22-39.

SANTOS, C. e BR O N STEIN , O . (1978). "M eta-urbanização - o caso do Rio de Janeiro". R evista deA dministração M unicipal, vol. 25, n. 149, pp. 6-34.

SAN TOS, W. G. (1987). "A trágica condição da política social". In: ABRAN CH ES, S.; SANTOS, W. e COIMBRA, M. Política social e combate à pobreza. Rio de Janeiro, Jorge Zahar Editor.

SASSEN, S. (1991). The Global City: N ew York, London, Tokyo. Princeton, Princeton U niversity Press.

SEADE, Fundação (1992). Pesqui sa de condi ções devida: uma abordagem multi ssetorial. São Paulo, Fundação Seade.

SEN, Amartya (1989). "Co-operation, I nequality, and the Family". In: M CN ICO LL, G. e CAIN, M. (orgs.). R ural Development and Population: I nstitutions and Policy. Suplemento a Population and D evelopment R eview, vol. 15, pp. 61-76.

SI BSIG (1995). R esumenes de la V C onferencia y curso I beroamericano sobre Si stemas de I nformación Geográfica. M endoza, Argentina, SI BSIG/ CIFOT/ DAIS.

SKOPCO L, T. (1992). Protecting Soldiers and M others: The Political Origins of Social Policy in the U nited States Cambridge, $\mathrm{H}$ arvard U niversity Press.

SM O LKA, M . (1987). "Para uma reflexão sobre o processo de estruturação interna das cidades brasileiras: 0 caso do Rio de J aneiro". Espaço e D ebates, n. 21.

ST REN , R. (1995). U rban R esearch in theD evel oping World - Latin A mérica. Toronto, Center for U rban and Community Studies.

SYDEN STRICKER-NETO, J. (2002). "Population and Environment in Amazônia. From J ust the N umbers to What Really Counts". In: HOGAN , D . J.; BERQU Ó; E. e COSTA, H. S. M. Population and Environment in Brazil. Campinas, CN PD , ABEP, N EPO , pp. 55-76. 
TASCHNER, S. P. e BÓGUS, L. (2000). "A cidade dos anéis: São Paulo". In: QU EIROZ, L.C. (org.). O futurodasmetrópoles des gualdadesegovernabilidade. Rio de Janeiro, Revan/ Fase.

TAYLO R, D . R. (org.) (1991). Geographic I nformation System: The M icrocomputer and the M odern Cartography. Oxford, Pergamon Press.

TITM U SS, R. (1963). Essays on the Welfare State. Surrey, U nwin Brothers.

TOPAL OV, C. (1974). LesPromoteursI mobiliers. Paris, M outon.

TORRES, H. (2002). Social Policies for the Urban Poor: The R ole of Population Information. U N FPA C ountry Support Team for Latin American and the Caribbean. Working Papers Series CST / LAC, n. 24.

--------- (1997). D esigualdade ambiental em São Paulo. Campinas, IFCH U nicamp, tese de doutorado.

TORRES, H . eCOELH O, G. (2001). "Primary Education and Residential Segregation in the M unicipality of São Paulo: A Study U sing Geographic Information Systems". Trabalho apresentado no Encontro "Segregation in the City". Cambridge, EU A, Lincoln Institute of L and Policy.

TORRES, H . e M ARQ U ES, E. (2002). "Tamanho populacional das favelas paulistanas. O u os grandes números e a falência do debate so bre a M etrópole". O uro Preto: trabalho apresentado no Encontro daAssociação Brasileira de Estudos Populacionais- Abep, nov. 2002.

--------- (2002). "R eflexões sobre a hiperperiferia: novas e vel has faces da pobreza no entorno metropolitano". R evista Brasileira de Estudos U rbanos e R egionais, n. 4, pp. 49-70.

U N D P at alii. (1998). D esenvolvimento humano econdições devida: indicadoresbrasileiros. Brasília, U NDP.

U N D P (2000). H uman D evelopment R eport 2000. N ew York, U nited N ations.

VALLADARES, L. e COELH O, M. (1987). "Pobreza urbana e mercado de trabalho: uma análise bibliográfica". In: 0 quese develer em Ciências Sociaisno Brasil, n. 2. São Paulo, Anpocs/ Córtex.

(1995). "U rban Research in Brazil and Venezuela - Towards an Agenda for the 1990s". In: ST REN , R. (org.). U rban R esearch in theD eveloping World - Latin A merica. Toronto, Center for U rban and Community Studies.

VALLADARES, L. e PRETECEILLE, E. (2000). "Favela, favelas: unidade ou diversidade da favela carioca". In: Q U EIROZ, L . C . O futuro das metrópoles desigualdadese governabilidade. Rio de J aneiro, O bservatório/ Revan/ Fase.

VETTER, D. (1975). The I mpact on the Metropolitan System of the Interpersonal and Spatial D istribution of R eal and M onetary Income: ThecC ase of GrandeR io. Comparative U rbanization Series. U niversity of California, L os Angeles.

VETTER, D; MASSENA, R. e RODRIGUES, E. (1979). "Espaço, valor da terra e eqüidade dos investimentos em infra-estrutura no M unicípio do Rio de Janeiro". Re vista Brasileira de Geografia, vol. 41 (1-2), pp. 32-71.

VETTER, D.; PINTO , D.; FRIEDRICH , O . e M ASSEN A, R. (1981). “A apropriação dos benefícios das ações do Estado em áreas urbanas: seus determinantes e análise através da ecologia fatorial". Espaço e D ebates, vol. 1(4), pp. 5-37. 
VILLAÇA, F. (2000). Espaço intra-urbano no Brasil. São Paulo, Fapesp/ Lincoln Institute/ N obel.

(1999). "E feitos do espaço sobre o social na metrópole brasileira". In: SOU ZA, M. A. (org.). M etrópole e gl obalização: conhecendo a cidade de São Paulo. São Paulo, Cedesp.

VISVALIN GAM , M . (1991). "Areal U nits and the Linking of D ata: Some Conceptual I ssues". I n: WO RRAL, L. (org.). Spatial A nalysi sand Spatial PolicyU sing GI S. L ondon, Belhaven Press, pp. 13-37.

WACQU ANT, L. (2001). Oscondenados da cidade. Rio de Janeiro, Revan.

WAL D IN GER, R. (1996). Still thePromised C ity? Cambridge, U niversity of H arvard Press.

WATSO N, G. (1992). Water and Sanitation in São Paulo, Brazil: Succesful Strategies for Ser viceProvis on in Low-incomeC ommunities. C ambridge, dissertação de mestrado apresentada no MIT, EUA.

WILSO N, William (1990). The Truly Disadvantaged: The Inner City, the U nderdass, and Public Policy. Chicago, U niversity of Chicago Press.

WO RBOYS, M . F. (1995). GIS, a Computing Perspective. London, Taylor Francis.

WORLD BANK (1999). Entering the 21`. century: World Development R eport 1999/ 2000. O xford, O xford U niversity Press.

WORRAL, L. (org.) (1991). Spatial A nalysis and Spatial Policy U sing GIS. London, Belhaven Press.

(1990). Geographic I nformation Systems. D evelopment and A pplications. London, Belhaven Press.

ZAJCZYK, F. (1996). "The Social M orphology of the New U rban Poor in a Wealthy I talian C ity: The C ase of M ilan". In: M I N G I O N E, E. U rban Pover tyand theU nderclass Blackwell Publications.

R ESUMO - ESTE ESTUDO busca atualizar o debate sobre a segregação urbana no Brasil, com base nos dados do Censo D emográfico de 2000 e da utilização de Sistemas de I nformação G eográfica. Sustentamos que o modelo centro-periferia é uma simplificação genérica da forma urbana, sendo a periferia de São Paulo heterogênea, o que acarreta importantes conseqüências para as políticas públicas.

A BSTRACT - THIS STUDY intends to revisit the urban segregation debate in Brazil, taking into account new data from the $2000 \mathrm{D}$ emographic $C$ ensus and the use of geographic information systems. We argue that the center-periphery model is a rough simplification of the urban form, and that the São Paulo outskirts are heterogeneous, with important consequences for public policies.

H aroldo Tor resé pesquisador do C ebrap e do Centro de Estudos da M etrópole (CEM ); Eduardo M arques é professor do D epartamento de Ciência Política de U SP e pesquisador do Cebrap e do CEM ; Maria Paula Ferreira é técnica da Fundação Seade e consultora do CEM e Sandra Bitar é pesquisadora do CEM .

U ma versão preliminar deste trabalho em inglês foi apresentada no "Workshop on U rban Governance and I ntra-U rban D ifferentials in Latin American M etropolitan Areas" realizado em Austin, Texas (EU A), em novembro de 2002, e organizado pela U niversidade do Texas. Tradução de Lenita M aria Esteves. 